Research Article

\title{
Mechanical and Acoustic Responses of Brittle Geomaterials with a Hole under a Compressive Disturbance
}

\author{
Peng Li $\mathbb{D}^{1,2,3}$ Yun-Quan $W u \mathbb{D}^{1,2,3}$ and Ying Zhang ${ }^{1,2,3}$ \\ ${ }^{1}$ School of Civil and Resource Engineering, University of Science and Technology Beijing, Beijing 100083, China \\ ${ }^{2}$ Key Laboratory of High-Efficient Mining and Safety of Metal Mines (Ministry of Education of China), \\ University of Science and Technology Beijing, Beijing 100083, China \\ ${ }^{3}$ Beijing Key Laboratory of Urban Underground Space Engineering, University of Science and Technology Beijing, \\ Beijing 100083, China
}

Correspondence should be addressed to Yun-Quan Wu; wu_yunquan@163.com

Received 3 June 2021; Accepted 3 August 2021; Published 12 August 2021

Academic Editor: Xin Cai

Copyright $(2021$ Peng Li et al. This is an open access article distributed under the Creative Commons Attribution License, which permits unrestricted use, distribution, and reproduction in any medium, provided the original work is properly cited.

The objective of this article was to investigate the acoustic emission (AE) precursor information and crack propagation mechanism of brittle granite specimens containing a hole under uniaxial compression using $\mathrm{AE}$ and digital image correlation (DIC) techniques. The results show that the existence of the opening in the specimen leads to the degradation of the mechanical properties, and the stress-strain curve exhibits several stress drops. Each deformation stage of rock had different AE characteristics, so AE signals can be used to characterize the microscopic damage evolution of rock and predict the macroscopic failure process of the surrounding rock of the opening. The deformation field evolution process of the specimen containing an opening gradually develops from a uniform distribution to prominent local deformation, and the deformation of the local area near the opening is greater than that of other areas. The initiation of cracks begins around the opening, and the propagation of tensile cracks around the opening is primarily influenced by the nucleation and propagation in the strain localization area. The crack propagation evolution derived from DIC images can be combined with AE monitoring to accurately reveal the deformation and failure mechanism of the intact specimen containing an opening.

\section{Introduction}

The use of underground caverns has been increasing, and cavern stability is an important prerequisite to ensure the safety of personnel and equipment during the construction and operation of underground engineering [1-3]. In recent years, with the rapid development of underground rock engineering, such as mining and tunnel excavation, the stability of underground caverns has become increasingly complicated. The underground caverns destroy the original equilibrium stress state of the rock mass during excavation, which causes a series of complex mechanical response behaviors related to stress redistribution in the surrounding rock mass $[4,5]$. The failure of surrounding rock generally shows the formation and aggregation of cracks and the interpenetration of multiple cracks, which causes deformation, spalling, and collapse of the rock mass on the excavation face and even dynamic disasters such as rock bursts $[6,7]$. For example, the surrounding rocks of underground tunnels in the Sanshandao gold mine, Jinping hydropower station [8], and AECL's Underground Research Laboratory [9] have experienced complex failure patterns. Therefore, the mechanical response behavior and stability of the surrounding rock of underground openings have become key scientific problems in the field of rock mechanics.

Numerous studies have been performed to study the failure mechanism and stability of the surrounding rock of the underground opening. As early as the 1970s, Lajtai and Lajtai [10] suggested that three main types of failure cracks around circular caverns occurred under relatively low confining pressure: primary tensile cracks, secondary (remote) cracks, and shear (normal shear and oblique shear) cracks. The primary tensile 
cracks propagated along the direction of maximum principal stress, while remote cracks and shear cracks deviated from the direction of maximum principal stress and intersected, and these cracks constituted the basic shape of the failure mode of the specimens. Carter et al. [11] studied the development of cracks around the opening in granite samples with a circular cavern under uniaxial loading and observed that the fracture transferred from a primary crack to a remote crack and then to a compression crack. Fakhimi et al. [12] found that the failure modes of the specimens not only had visible cracks but also formed two V-type notches at the transverse boundary of the cavity and believed that the damage in the two notches and the plastic behavior of the rock in the region were the causes of the cracks. Zhao et al. [13] concluded that fracture modes around a cavity can be characterized as tensile cracks at the roof, compression cracks at two sidewalls, and remote or secondary cracks around the cavity, which were related to the size of the cavity. Li et al. [14] stated that the geometric shape of chambers was an important factor affecting the strength and boundary tangential stress distribution of specimens. Xu et al. [15] suggested that tensile fracture was easily formed at the top and bottom of the circular chamber, while a shear fracture could be easily found at both sides. With an increase in the circular cavity size and a decrease in the rock pillar relative size, shear cracks were dominant. Weng et al. [16] investigated the deformation and failure process of granite specimens containing round chambers under uniaxial loading and found that the failure of round chambers started with the main tensile crack in the sample area, and then shear cracks appeared on the sidewall before shear and tensile cracks appeared in other areas. Feng et al. [17] believed that the failure strength of the cavity is a function of the inclination angle of the structure surface and the friction coefficient, and the critical inclination angle of the structure surface leading to the failure of the cavity largely depended on the friction coefficient. The above studies explored the failure modes and failure mechanisms of surrounding rock under different working conditions, which has greatly improved the understanding of underground engineering cavern disasters.

Previous investigations have primarily focused on the macroscopic failure mechanics characteristics of cavern rock, but research on the evolution of $\mathrm{AE}$ characteristics and mesoscopic failure mechanism of cavern rock is not sufficient. Studying the relationship between AE characteristics and rock fracture evolution during rock failure can further reveal the failure mechanism of rock. To that end, AE monitoring technology and the DIC method are employed to perform uniaxial loading tests on intact rock specimens and intact rock specimens containing an opening under a low strain rate. The AE behavior, deformation field evolution characteristics, failure evolution process, and failure mode of the samples were compared and analyzed, and the fracture structure change and mesoscopic damage evolution law of the chamber surrounding rock were obtained. The research results can not only further enrich and perfect the theoretical system of the chamber surrounding rock stability but also provide a scientific basis for disaster mechanism analysis and stability evaluation of underground openings, which has important theoretical value and guiding significance.

\section{Experiments}

2.1. Granite Sample Preparation. Specimens extracted from the same large hard granite block with good geometrical integrity and petrographic uniformity in Laizhou city, China, were employed in this investigation. To reduce the influence of man-made damage, the intact granite specimens were first processed by mechanical cutting, which causes less physical damage to the specimens and remaining block than the drilling-blasting method. At present, a reasonable representative size of rock specimens or rock-like specimens used to simulate the surrounding rocks of the underground cavity has not been discussed, and there is no unified understanding [16]. Most scholars worldwide used cuboid specimens to carry out physical simulations and numerical simulations of underground openings, but there is no unified standard for the size of specimens, which were set according to their test needs. To explore the physical and mechanical behavior of the surrounding rock under uniaxial compression, intact cuboid granite specimens with heights, widths, and thicknesses of $100 \mathrm{~mm}, 35 \mathrm{~mm}$, and $35 \mathrm{~mm}$, respectively, were first prepared. The aspect ratio of the sample was 2.86, which conformed to the test standard of the uniaxial loading test recommended by the International Society of Rock Mechanics (ISRM) [5] and can ensure that the central part of the specimen bore uniform stress during loading. After the completion of the intact specimen processing, circular openings with a diameter of $10 \mathrm{~mm}$ were fabricated by an improved high-pressure water jet cutting machine in the center of the intact granite samples. Highpressure water mixed with garnet sand was sprayed from a nozzle with a diameter of $0.5 \mathrm{~mm}$; this method can produce openings of any size and can ensure the smoothness of the opening surface and protect the prepared samples from damage. The straightforward model and size of the intact specimen with an opening are plotted in Figure 1(a). Prior to testing, the loading ends of all samples were carefully polished to minimize the influence of end effects during loading [18]. Physical photos of the specimens finally used for testing are presented in Figure 1(b). In Figure 1(b), the number represents the type of sample, i.e., UI denotes the intact sample, UC stands for the intact sample containing an opening, and the following digits represent the serial number of the samples. In all tests, the specimens were processed and tested in the same way, so the test results were comparable. Note that the intact samples were used for comparative analysis.

2.2. Digital Image Correlation (DIC) System. DIC technology is an optical noncontact particle tracking measurement technique that can determine the displacement of the speckle in a digital image and has been widely adopted to study the crack evolution on the surface of rock specimens [19]. This experiment requires a digital image acquisition system and digital image correlation calculation software. The digital image acquisition system includes loading equipment, incandescent lamps, calibration equipment, high-speed cameras, and VIC-3D digital image-related 


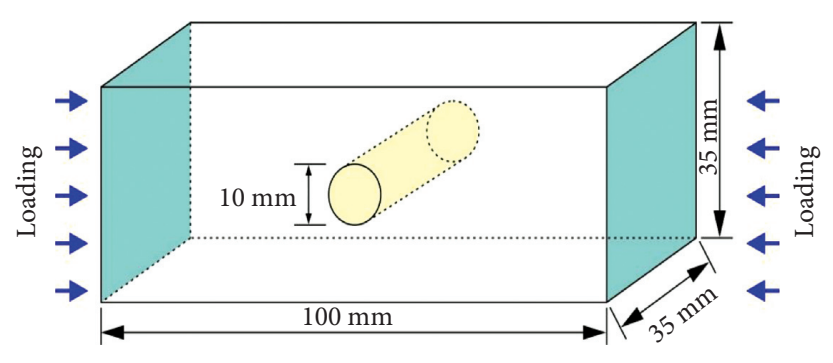

(a)

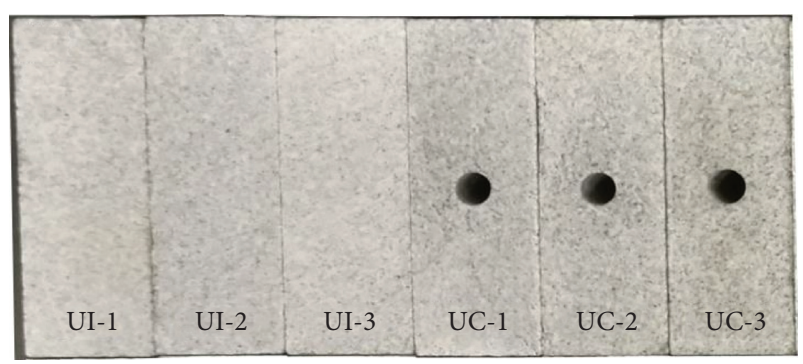

(b)

FIGURE 1: Specimen model and size of the intact sample containing an opening (a) and physical photos of the test samples (b).

analysis software. The in-plane displacement accuracy was $\pm 10 \mathrm{~nm}$, the global strain accuracy was $\pm 0.01 \%$, and the frame rate was up to $2000 \mathrm{fps}$. Before a test, a thin layer of matte white paint was sprayed uniformly on the photographed surface of the specimens. After the white paint dried, a special speckle sticker was applied to completely cover the surface of the specimens to form a random artificial spot pattern to ensure that the speckle sticker could cover the specimen surface firmly and cut off the speckle sticker at the opening (Figure 2). Two cameras were fixed on a tripod, and the camera position, focal length, and light source were adjusted according to the imaging quality of the sample on the computer so that the scattered spots on the sample surface could be identified, ensuring that the image on the specimen surface could be continuously and completely recorded during the whole test process. The highspeed camera was placed perpendicular to the front surface of the specimen; an incandescent lamp was used to provide the required light source to capture a clear image of the specimen, which was stored on the computer for subsequent processing. During the test, the high-speed camera was set up to capture high-resolution images continuously and automatically at a frame rate of five pictures per second, which is sufficient to provide specific details of deformation field evolution and crack propagation [19].

2.3. Acoustic Emission (AE) Testing Equipment. The AE test can be used to study the development of microcracks and the damage evolution of materials on a mesoscale [20]. At present, the $\mathrm{AE}$ signal characterization parameters are mainly obtained by processing the output waveform, and the typical AE signal waveform parameter diagram is illustrated in Figure 3. During the loading process, the AE signal source is generated in the sample. After propagation, it is finally detected by the sensor installed on the specimen. In this study, a PCI-2 six-channel AE system (Figure 4(a)) was adopted to record the AE signals produced during uniaxial compression. The AE monitoring system can realize 18-bit A/D conversion, with a high sampling rate of $40 \mathrm{MHz}$ per channel, and can continuously store $\mathrm{AE}$ waveforms at a rate of $10 \mathrm{MHz} / \mathrm{s}$. AE exhibits powerful performance in waveform acquisition and analysis and can effectively reduce sampling noise. Furthermore, the R6 $\alpha$ resonant high sensitivity sensor (Figure 4(b)) was adopted, which has high sensitivity and low resonance frequency characteristics. The
AE signals measured in the sensors were amplified by a gain of $40 \mathrm{~dB}$ with preamplifiers, and the trigger threshold of the $\mathrm{AE}$ was set to $45 \mathrm{~dB}$ to avoid the influence of electronic or environmental noise. All waveform data were automatically recorded at a data acquisition rate of $1 \mathrm{MHz}$. To better cover the specimen and accurately record AE signals, a total of four $\mathrm{AE}$ sensors were employed, and two $\mathrm{AE}$ sensors were uniformly arranged on the left and right sides of the specimen (Figure 4(b)). To ensure firm adhesion between the sensor and the sample surface, the sensor was directly connected to the sample surface with adhesive tape, and Vaseline was applied between the sensor and the sample surface. When the uniaxial loading test started, AE equipment was started synchronously, and AE signals generated by specimen rupture during loading were obtained in real time. During the experiment, the testing machine and $\mathrm{AE}$ host were grounded to eliminate the noise induced by the current.

2.4. Loading Procedure. A servo-controlled rock mechanics machine (TAW-3000) with a maximum axial load of $3000 \mathrm{kN}$ was adopted in the loading system. A photograph of the test system is shown in Figure 5. During the loading process, the axial load and displacement of the specimen can be automatically collected and recorded by the loading equipment in real time. Moreover, the test system has the advantages of various loading methods, stable equipment performance, and high control precision.

The uniaxial compression experiment was loaded by displacement control. To avoid the noise signal caused by friction and slip of the specimen in the initial loading stage, the specimen was preloaded to $2 \mathrm{kN}$ and then loaded at a constant displacement speed of $0.1 \mathrm{~mm} / \mathrm{min}$ until the specimen failed. A sufficiently low loading speed can ensure that the samples remained in quasistatic equilibrium during loading. At the same time, the AE and DIC measurements were performed synchronously to record the deformation evolution and $\mathrm{AE}$ signals corresponding to the stress-strain response of the samples.

\section{Mechanical and AE Behavior}

3.1. Mechanical Behavior. Figure 6 presents the stress-strain curves of the intact specimen (i.e., UI-2) and the intact specimen containing an opening (i.e., UC-3). It can be 


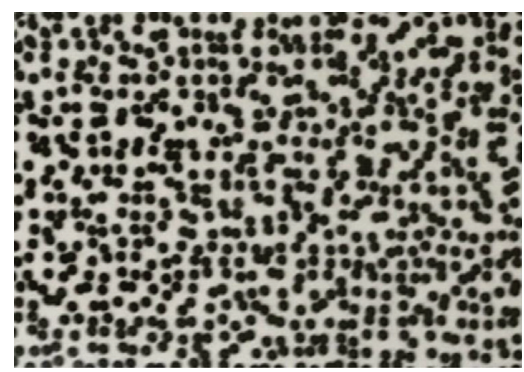

(a)

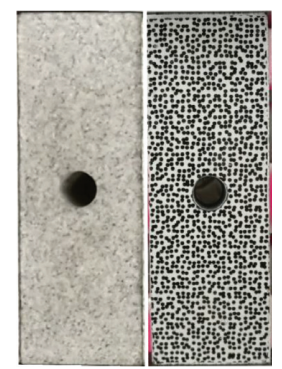

(b)

FIGURE 2: Fabrication of speckles on the specimen surface: special speckle sticker (a) and original specimen and speckled specimen (b).

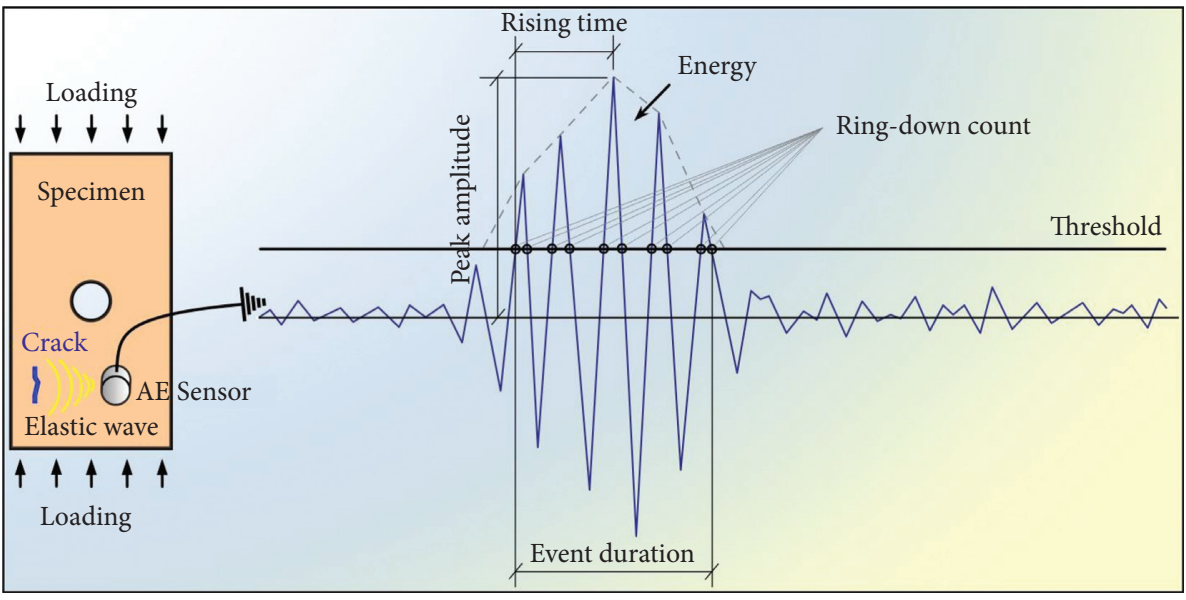

Figure 3: Illustration of typical AE waveform characteristics.

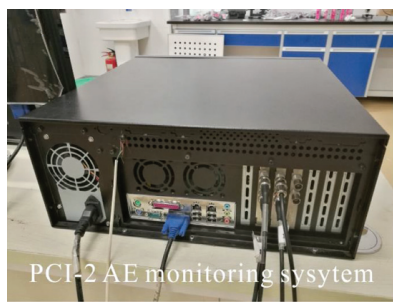

(a)

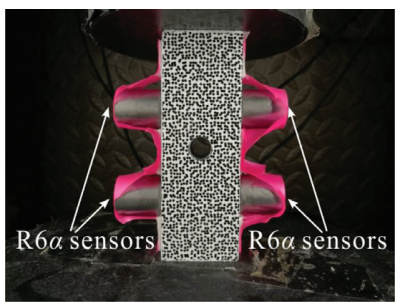

(b)

Figure 4: PCI-2 AE system (a) and AE sensor arrangement (b).

observed that the existence of the opening has a remarkable influence on the mechanical properties of the samples. During axial compression, the stress of the intact sample increases almost linearly with strain until it reaches the peak strength. In contrast, the intact sample containing opening experiences an obvious plastic stage before failure, and the phenomenon of multiple stress drops appears. In addition, almost all axial stresses suddenly drop from the peak point, which means that brittle failure appears in the granite specimens.

The average peak strength of the intact sample is 251.27 MPa, indicating the hard characteristics of the rock material. For the intact specimen containing an opening, the average peak strength drops sharply to $179.27 \mathrm{MPa}$, which is $28.65 \%$ lower than the intact specimen. The existence of the opening reduces the strength of the samples, which is mainly because the existence of the opening reduces the relative size and the load-bearing capacity of the specimens. The elastic modulus is determined using the slope of the straight-line section of the stress-strain curve. The elastic modulus of the intact specimen is $34.61 \mathrm{GPa}$ and that of the intact specimen containing an opening decreases to $30.58 \mathrm{GPa}$, showing a decrease of $11.64 \%$. The influence of opening on the elastic modulus is weaker than that on the peak strength.

3.2. AE Event Characteristics. AE counts refer to the number of AE events per unit of time. Figure 7 shows the evolution characteristics of AE counts, AE cumulative counts, and the corresponding stress-time curves of the intact sample and 


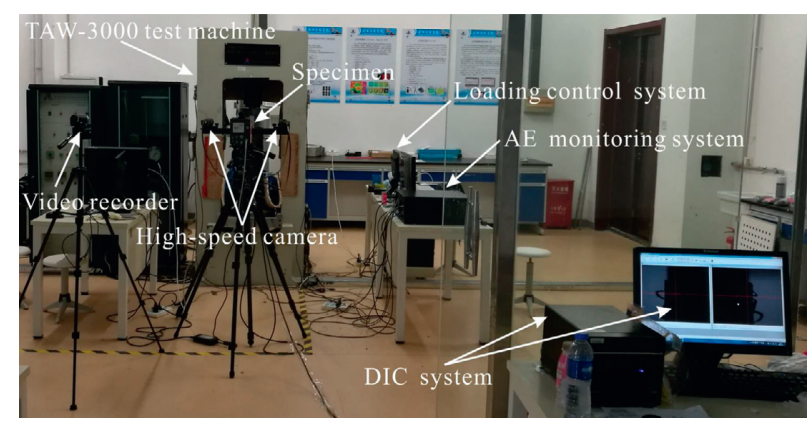

FIgURE 5: Experimental setup for the uniaxial compression test.

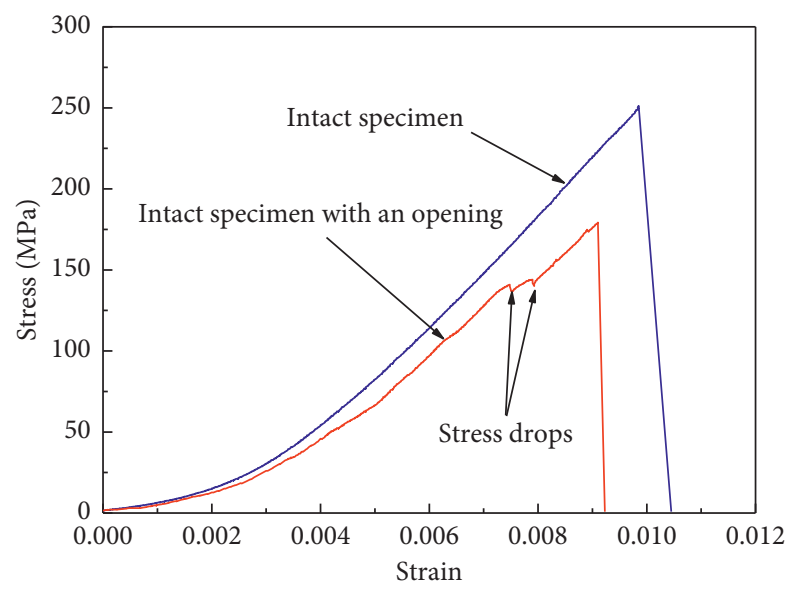

FIGURE 6: Stress-strain curves of the intact sample and the intact sample containing an opening under uniaxial compression.

the intact specimen containing an opening during uniaxial loading. The changing trend of the AE counts of these two types of specimens is generally similar. The intact specimen, especially the intact specimen containing an opening, begins to respond to the loading conditions at the initial compaction stage and produces a small amount of AE signals, which indicates that the friction between particles, crystal dislocation, crack initiation, and propagation activities in the samples are active during the loading. In the elastic deformation and stable crack growth stages, the fluctuation of $\mathrm{AE}$ counts is relatively "stable," while the AE count curve shows several large fluctuations in the unstable crack growth stage, and the AE count rapidly decreases from a high value to a low value, which could be used as a sign of rapid crack initiation, propagation, or coalescence in the local region of the specimen. This process continues until the overall failure of the specimens.

In addition, there are some differences in the characteristics of AE events generated by these two types of samples at the initial stage of loading. The intact specimen produces few AE events at the beginning of loading, while the intact specimen containing an opening produces a larger number of $\mathrm{AE}$ events, implying that the existence of the opening promotes the obvious crack initiation phenomenon at the initial loading stage, leading to the microfracture of the specimen.
3.3. AE Energy Evolution Characteristics. AE energy represents the AE signal energy released by materials per unit time. Figure 8 shows the evolution characteristics of the $\mathrm{AE}$ energy and AE cumulative energy and the corresponding stress-time curves of the intact specimen and intact specimen containing an opening under uniaxial loading. For the intact specimen, the energy release is small in the initial compaction stage, elastic deformation stage, and stable crack propagation stage. The $\mathrm{AE}$ energy curve is a horizontal straight line close to zero, and the intact specimen has a strong self-adjusting ability to the external load. Until the unstable crack growth stage, AE energy release is obvious, which means that new cracks appear in the specimen, and the maximum AE energy occurs at the peak point. The $\mathrm{AE}$ energy characteristics of the intact sample are consistent with the expected response law of brittle rock materials [21]. For the intact specimen containing an opening, there is no noticeable AE energy release in the initial compaction stage, which is similar to the intact specimen. When the load increases in the elastic deformation and stable crack propagation stages, a small amount of AE energy release is observed, which indicates that the specimen reacts to the loading conditions, and it leads to small-scale fracture. The energy release time of the intact specimens containing an opening is earlier than that of the intact specimens, which is mainly because the opening reduced the adaptive capacity of 


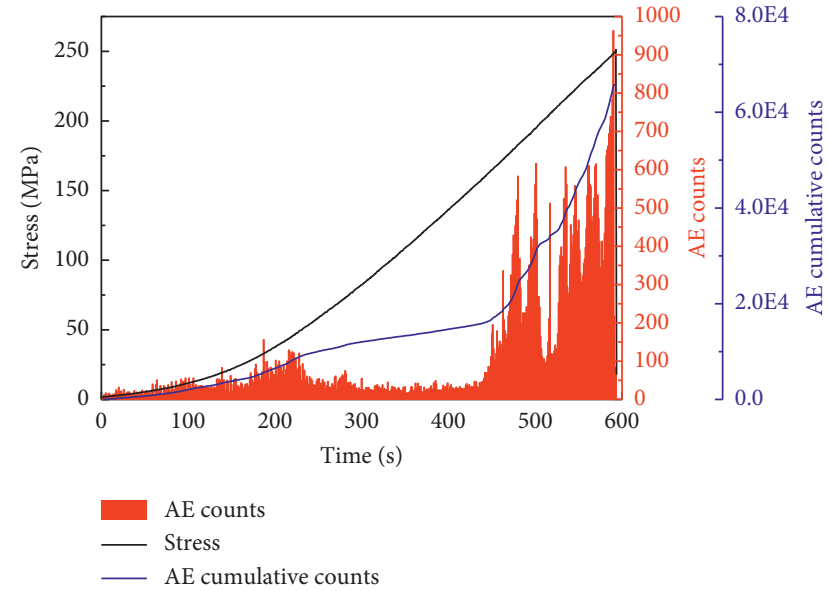

(a)

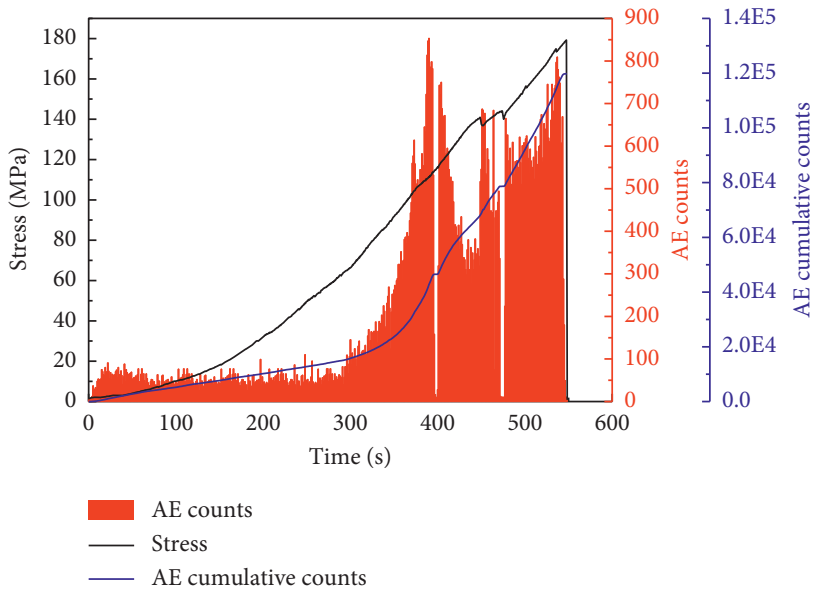

(b)

FIgURE 7: AE counts and cumulative count evolution of the intact specimen (a) and the intact specimen containing an opening (b).

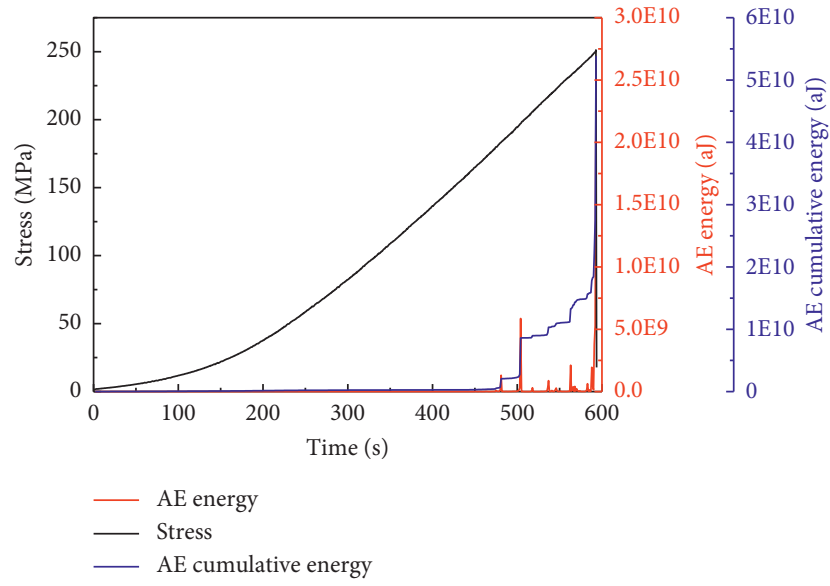

(a)

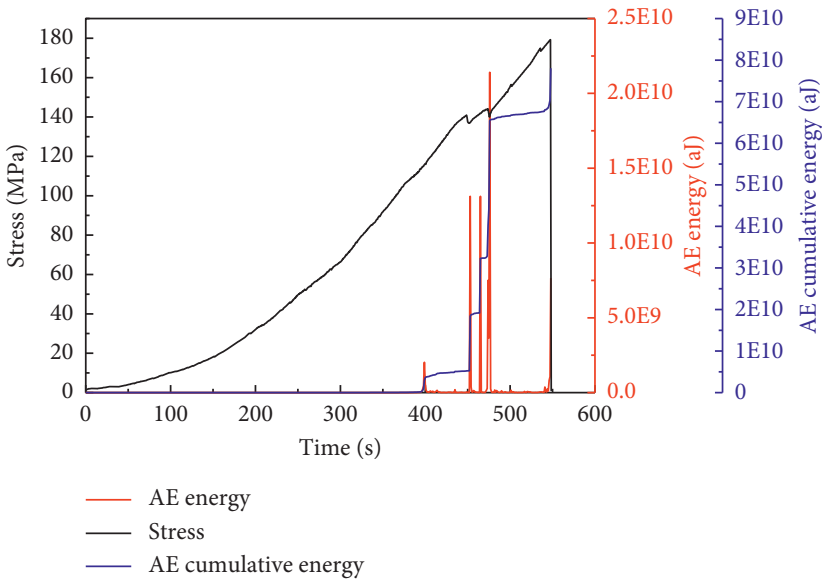

(b)

FIgURE 8: AE energy and cumulative energy evolution of the intact specimen (a) and the intact specimen containing an opening (b).

the specimen to the external load, and the high stress concentration around the opening intensified the early crack initiation. In the unstable crack propagation and residual strength stages, a large number of cracks are generated, expanded, or coalesced, which leads to multiple energy release processes. With the coalescence of small-scale cracks, large-scale cracks are formed until the macrocracks lead to sample failure, which releases more energy.

Different from the intact specimen, the most concentrated AE energy release stage of the intact specimen containing an opening does not appear at the peak point but occurs when the stress-strain curve produces a stress drop at a certain time in the process of deformation and failure. This phenomenon may be because the energy of the intact specimen can accumulate all the time in the prepeak stage and then release suddenly at the peak point, while the energy of the intact specimen containing an opening is continuously released during crack propagation and coalescence [22]. Therefore, compared with the intact specimen, the existence of the opening changes the $\mathrm{AE}$ energy release characteristics of the specimen during loading. However, the AE energy of those two types of specimens shows accelerated release near the overall failure, indicating that there is a critical energy release in the specimens. Hence, the sudden increase in $\mathrm{AE}$ energy can be used as the precursor of specimen failure.

3.4. Correlation between $A E$ Counts and Energy. The $\mathrm{AE}$ counts and energy have a certain correlation with the stage characteristics of rock failure. Figure 9 shows the correlation of $\mathrm{AE}$ counts and energy of the intact sample and the intact specimen containing an opening during uniaxial compression. The relationship between the AE counts and energy of the tested specimens during deformation and failure has an approximately L-shaped distribution. The distribution range of $\mathrm{AE}$ counts of the intact sample and the intact specimen containing an opening is 10-900 times per second, and the distribution range of energy is $10^{9}-10^{10}$. When the $\mathrm{AE}$ energy is high (energy level is $10^{10}$ ), the $\mathrm{AE}$ counts are 


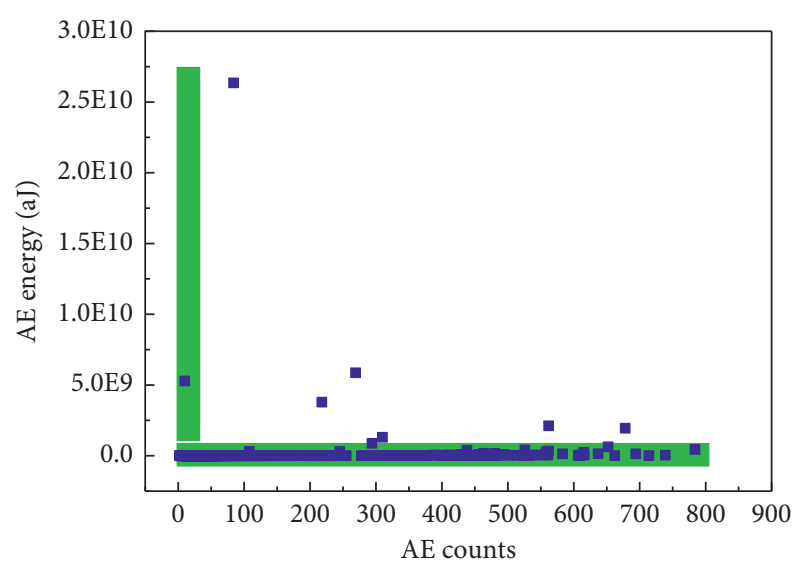

(a)

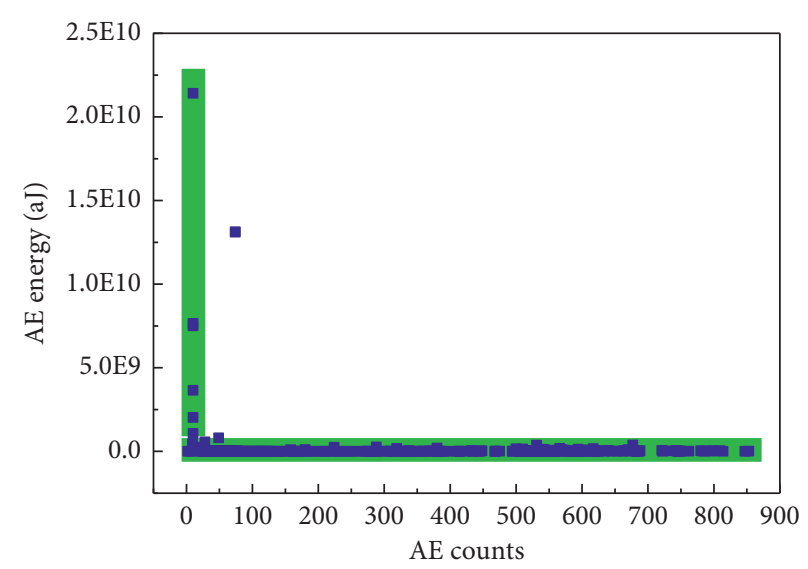

(b)

FIgURE 9: AE count-energy correlation of the intact specimen (a) and the intact specimen containing an opening (b).

low, which is close to 25 times per second. When the $\mathrm{AE}$ counts are high, approaching 700-900 times per second, the $\mathrm{AE}$ energy is low, with an energy level of $10^{9}$. The AE counts and energy of the two types of specimens during deformation and failure show the characteristics of high energy corresponding to small counts and low energy corresponding to large counts, suggesting that when the specimens fail, that is, when the AE energy release reaches a large level or the maximum, the $\mathrm{AE}$ counts are low and the $\mathrm{AE}$ activity is at a low level. This is a common feature of the tested specimens, which is less affected by the opening.

3.5. AE b-Value Evolution Characteristics. AE events are acoustic waves released by elastic properties during rock deformation and failure, which can be regarded as microseismic activity. Based on this, the related parameter $b$-value of the earthquake magnitude and frequency can be calculated. The $b$-value analysis can be used as an auxiliary means to characterize the deformation and failure process characteristics of the tested granite specimens. Gutenberg and Richter [23] determined the relationship between earthquake frequency and corresponding magnitude, also known as the famous G-R relationship, which has been widely used in the analysis and judgment of rock fracture precursors. The $\mathrm{G}-\mathrm{R}$ relationship can be expressed as

$$
\log _{10}(N)=a-b M,
$$

where $M$ is the magnitude of an earthquake; $N$ is the number of seismic events within $M \pm \Delta M$, which is considered to be the number of AE events of the specimens; and $a$ and $b$ are constants, where $b$ represents the slope.

The calculation method of the $b$-value can be found in the introduction provided by Li et al. [5]. Figure 10 shows the evolution of the $b$-value with time in the whole loading process of the intact sample and the intact sample containing an opening. Generally, the $b$-value curves of different specimens are different in shape under uniaxial loading, but the overall change characteristics are similar; that is, the $b$ value curves show fluctuating variation patterns during loading, which is the embodiment of the internal heterogeneity in granite, and then drops rapidly before the failure of the specimens. From the perspective of seismology, the $b$ value can be used to characterize the scale of magnitude distribution of $\mathrm{AE}$ events, thus measuring the relative number of small- and large-magnitude rupture events in rocks under compression. The larger the $b$-value is, the larger the proportion of small rupture events is, and vice versa [24]. From the initial loading to the peak point, the $b$-values of the intact sample and the intact sample with an opening are basically distributed in the range of $0.1-0.7$ and $0.1-0.9$, respectively, and the $b$-values sharply drop to the minimum until the samples fail, showing a trend of overall decline. The results indicate that the small-scale cracks are dominant in the two types of samples in the early stage of loading, and the large-scale fracture only appears near the moment when the overall failure of the sample occurs, which further reflects the nature of brittle failure of the tested granite materials. In addition, the evolution characteristics of the $b$-value also show that the internal stress of the specimen is constantly adjusted during loading, which mainly depends on the development of cracks. Before failure, the structure of the sample is still relatively complete. It can be concluded that the crack evolution of all samples in each deformation stage has both gradual and sudden development, showing complex evolution characteristics. Note that previous studies have shown that the $b$-value corresponding to the failure of a rock mass is generally less than 1.0 in laboratory tests, which is strongly supported by the research results of this study.

3.6. Correlation between AE Peak Frequency and Amplitude. The peak frequency of the AE signal and the corresponding amplitude are sensitive to the load change in the specimen. The evolution process of the amplitude and frequency is of great value to characterize the fracture characteristics of the specimen. Figure 11 shows the three-dimensional relationship diagram of the peak frequency-time-amplitude of the $\mathrm{AE}$ signal of the intact specimen and the intact specimen containing an opening under uniaxial loading, which is used to analyze the evolution law of the amplitude of the AE signal in 


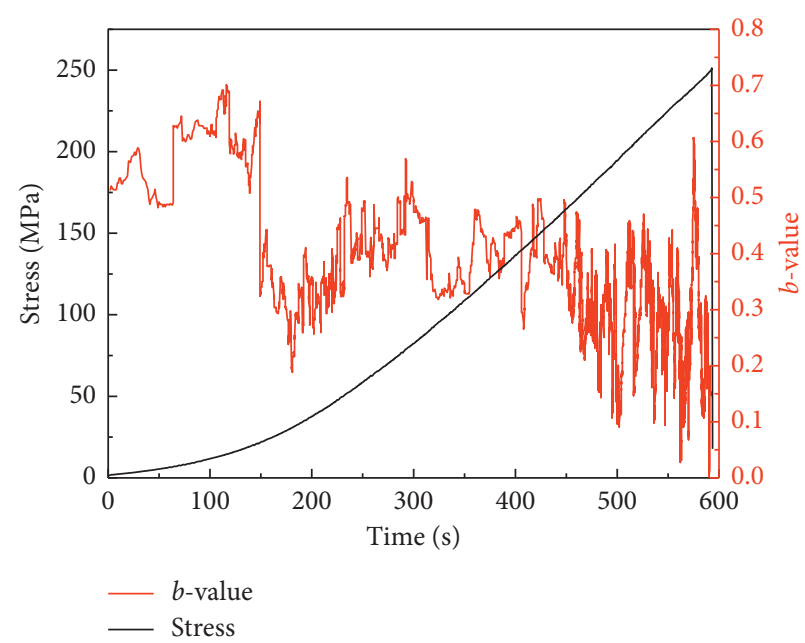

(a)

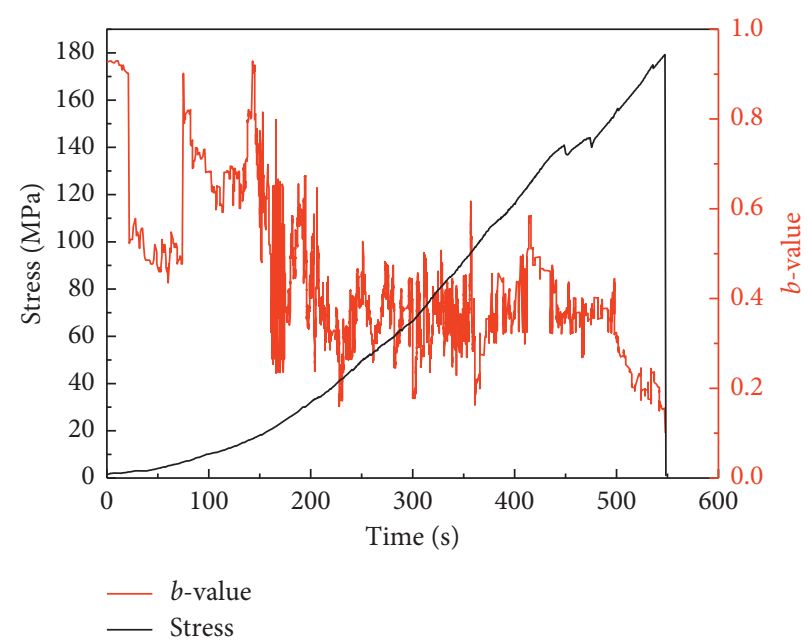

(b)

Figure 10: Evolution of $\mathrm{AE} b$-values of the intact specimen (a) and the intact specimens containing an opening (b).

low-, medium-, and high-frequency zones. The AE signals of all specimens are relatively rich, with a noticeable main frequency band in the frequency domains of $30-59 \mathrm{kHz}$ and $88-106 \mathrm{kHz}, \mathrm{AE}$ signals are distributed in the frequency domain of $110-500 \mathrm{kHz}$, and the peak frequency value distribution of $\mathrm{AE}$ signals is relatively uniform. In addition, in the low-frequency zone, the $\mathrm{AE}$ signals of all specimens are mainly of low amplitude $(<1130 \mathrm{mV}$ [25]). A small number of high-amplitude signals $(\geq 1130 \mathrm{mV})$ are generated in both the unstable fracture stage and residual strength stage, especially when the sample is damaged. In the middle- and high-frequency zones, the amplitude of the AE signal of all specimens is low, which is less than $1130 \mathrm{mV}$. The high-amplitude signals of all specimens are located in the low-frequency zone, and low-amplitude signals also exist in the low-frequency zone, while only low-amplitude signals appear in the middle- and high-frequency zones. De Santis and Tomor [26] believed that high-amplitude waveform signals generally concentrate in the low-frequency range, which indicates the release of high energy. Hence, it can be inferred that the $\mathrm{AE}$ signal with low frequency and high amplitude generated during the deformation of the sample means that the accumulated energy stored in the sample is released instantaneously.

In conclusion, the change trends of the $\mathrm{AE}$ counts, cumulative counts, energy, cumulative energy, $b$-value, peak frequency, and amplitude with time are generally consistent during uniaxial compression, which can well reflect the internal damage and failure process of the intact sample and the intact sample containing an opening. Note that there is no significant $\mathrm{AE}$ quiet period before the peak point of these two kinds of specimens. These parameters have a good ability to identify precursors and can be used as precursory signals to determine the failure of specimens. In particular, the cumulative counts and cumulative energy of $\mathrm{AE}$ events contain the AE information in the loading history, and their forms are simpler and more intuitive to extract the precursor points; thus, the two parameters can be more conveniently applied in actual rock engineering instability prediction.
Note that due to space constraints, the $\mathrm{AE}$ distribution characteristics of other specimens are not presented in the paper, but the test results are quite consistent.

\section{Analysis of the Deformation and Failure Mechanism}

4.1. Evolution Characteristics of the Deformation Field. To investigate the deformation evolution and crack propagation process of the intact specimen with an opening from a mesoscopic perspective, the DIC system was used to monitor the image evolution characteristics of the sample during deformation and failure. After postprocessing, the variation characteristics of the deformation field in terms of the displacement field and strain field during deformation and failure were obtained, and then the crack propagation evolution laws of specimens at different stress levels under uniaxial loading were analyzed and compared. Due to the high strength of the granite material used in this experiment, the deformation field on the specimen surface does not change significantly in the early stage of loading. Generally, noticeable crack growth occurs only in the stable and unstable crack growth stages. Therefore, based on the development characteristics of the stress-strain curve of the specimen and the evolution characteristics of $\mathrm{AE}$ events, some key stress points of the specimen in the stable and unstable crack propagation stages are chosen to discuss the evolution characteristics of the deformation field. In the deformation field nephogram to be analyzed later, $u$ represents the horizontal displacement field, $v$ denotes the vertical displacement field (parallel to the loading direction), and $\varepsilon_{1}$ represents the major principal strain field.

The stress-time-AE count curve of the intact specimen containing an opening is shown in Figure 12. Eight key stress points $(\mathrm{A}-\mathrm{H})$ are marked on the curve to analyze the evolution characteristics of the deformation field corresponding to these stress points. 


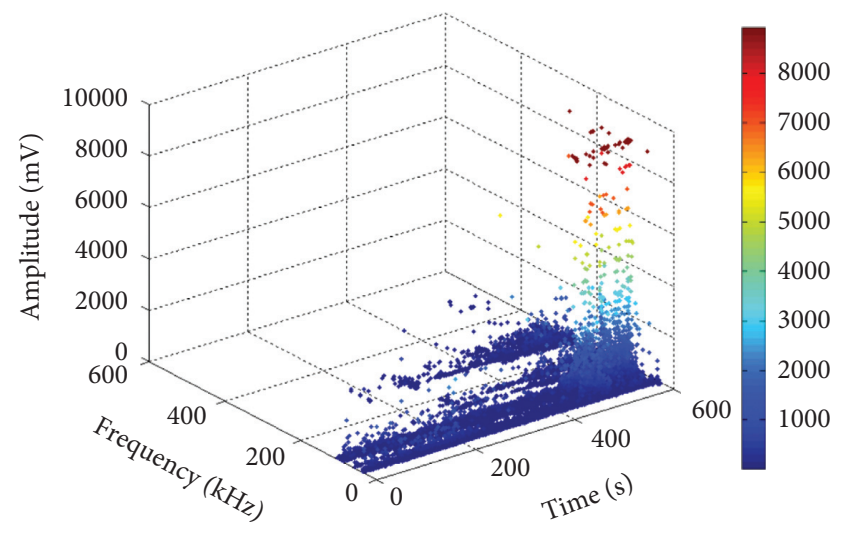

(a)

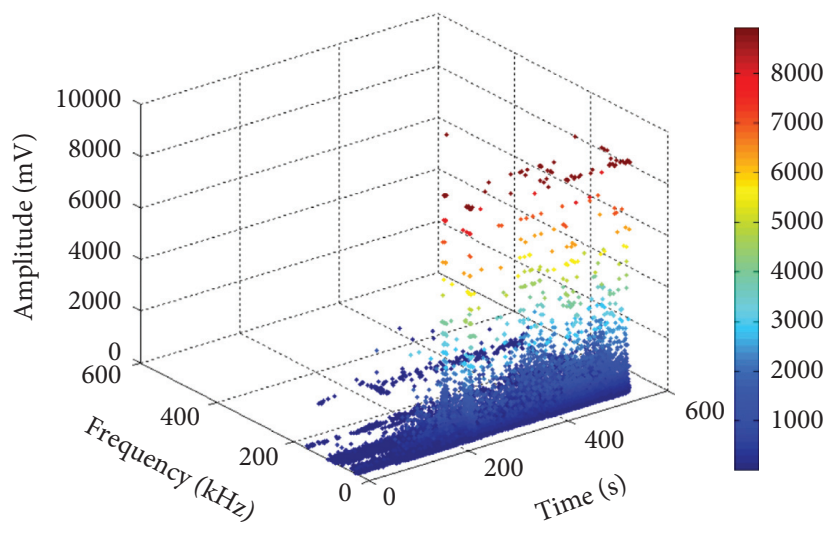

(b)

Figure 11: Three-dimensional distribution of the AE frequency-time-amplitude of the intact specimen (a) and the intact specimen containing an opening (b).

Figure 13 manifests the nephogram of the horizontal displacement field corresponding to the stress points marked in Figure 12, which clearly demonstrates the development of the horizontal displacement of the sample during loading. In general, the deformation of the specimen surface is approximately symmetrically distributed on the left and right sides of the opening. The left part of the sample has a negative horizontal displacement, while the right part has a positive horizontal displacement, indicating that the left surface of the opening moves to the left and the right surface of the opening moves to the right. As the load increased, the absolute value of the horizontal displacement increased gradually. Specifically, when loading to point A, the horizontal displacement contour of the specimen surface is symmetrically distributed on both sides of the opening in a $\mathrm{V}$-shape, and the displacement value is relatively large (Figure 13(a)), implying that the stress acting on the specimen is relatively uniform. As the load increases to point $\mathrm{B}$, the horizontal displacement further increases, and a vertical linear region appears between the two different displacement contour regions at the top and bottom of the opening (Figure 13(b)). Subsequently, the range and magnitude of the displacement area increase greatly. Several S-shaped symmetrical lines gradually appear on both sides of the vertical linear area in the middle of the displacement isoline (Figures 13(c)-13(g)), and two horizontal displacement increasing areas with vertical strip distribution are formed on both sides of the opening. When the peak strength is reached, the horizontal displacement field evolves into different symmetrical regions separated by these symmetrical lines. The horizontal displacement increasing region shifts to the lower left and upper right of the opening and extends to the top and bottom of the sample. The horizontal displacement rapidly increases to the maximum value of $0.334 \mathrm{~mm}$ (Figure 13(h)).

Figure 14 shows the nephogram of the vertical displacement field corresponding to the stress points marked in Figure 12. As the load increases, the displacement value gradually increases, which directly reflects the deformation of the specimen surface parallel to the loading direction after being loaded. When loading to point $\mathrm{A}$, the vertical displacement value is distributed in a horizontal gradient from the lower end to the upper end of the specimen (Figure 14(a)), and the displacement difference is small, which indicates that the influence of the existence of the opening on the displacement distribution of the specimen is not obvious at this time. When loading to point $B$, affected by the symmetric localization zone, the vertical displacement isoline becomes more disordered, and the displacement is distributed in a V-shape upward and downward with the opening as the center (Figure 14(b)), showing obvious discontinuous evolution characteristics. Then, the range and magnitude of the displacement increasing area continue to increase with increasing axial deformation, and two obvious displacement increasing zones are formed in the upper and lower parts of the opening. The displacement value in the center of the upper displacement increasing zone is the smallest, while the displacement value in the center of the lower displacement increasing zone is the largest (Figures 14(c)-14(g)). As the load increases to the peak level, the state of the vertical displacement field is similar to the displacement field at point $\mathrm{G}$, but the range of displacement increasing area further changes slightly, and the displacement value reaches the maximum value of $0.474 \mathrm{~mm}$ (Figure 14(h)).

Figure 15 shows the nephogram of the major principal strain field corresponding to the eight key stress points marked in Figure 12, which shows the important process of crack growth. Overall, the major principal strain field experiences an evolution process from a uniform distribution to the local protrusion of cracks, and finally, the strain in the crack area is significantly larger than that in other areas. Specifically, the major principal strain field is uniformly distributed when the stress level reaches point $A$, and the high strain zone first appears directly above and below the opening, forming a tensile stress concentration (Figure 15(a)). The tensile strength and elastic modulus of the granite sample tested in this study are $17.85 \mathrm{MPa}$ and $34.61 \mathrm{GPa}$, respectively, and the computed value of the maximum tensile strain, $\varepsilon_{1 \max }$, is $5.16 \times 10^{-4}$. The $\varepsilon_{1}$ value in 


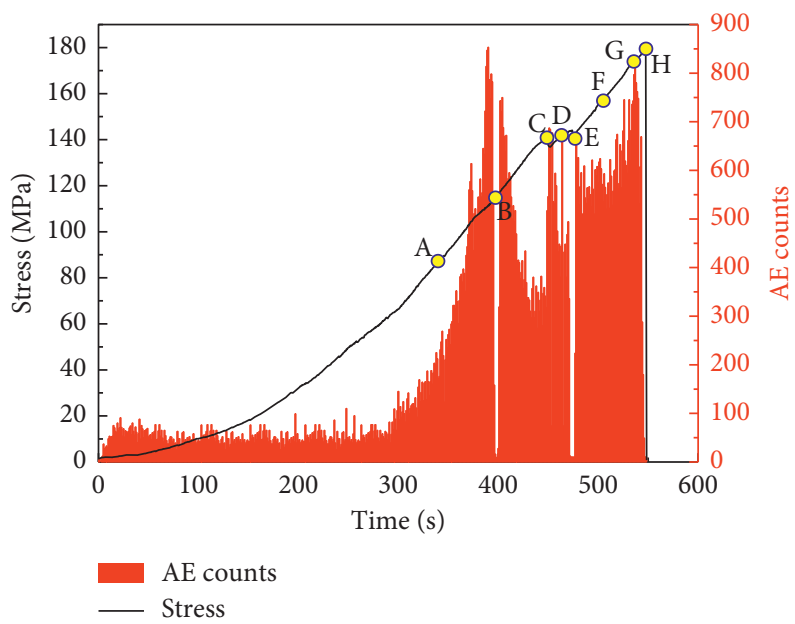

FIGURE 12: Stress-time-AE count curve of the intact specimen with an opening and the marked key stress points.

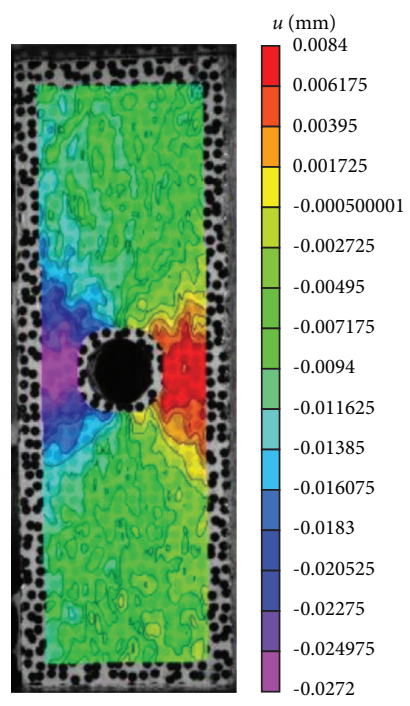

(a)

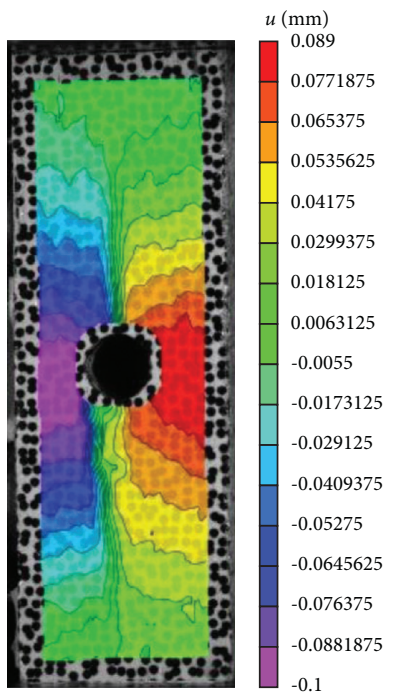

(e)

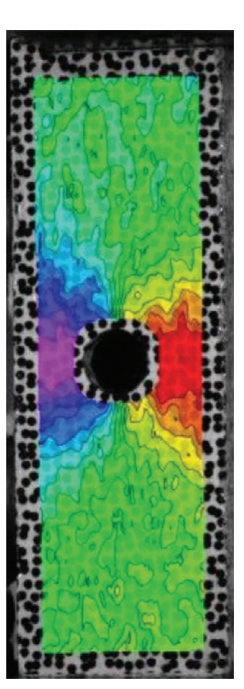

(b)

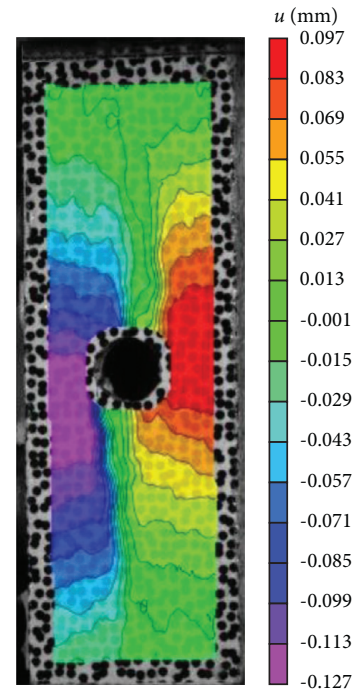

(f)
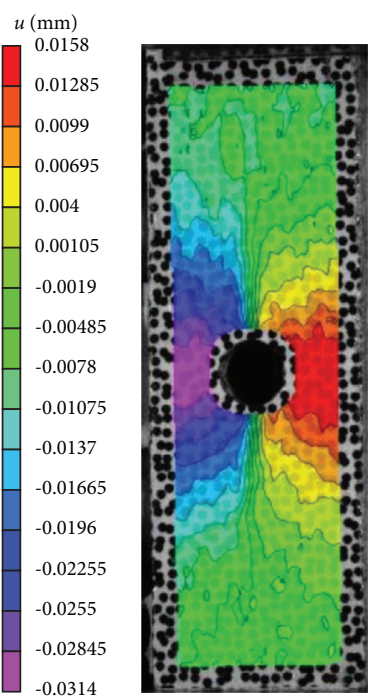

(c)

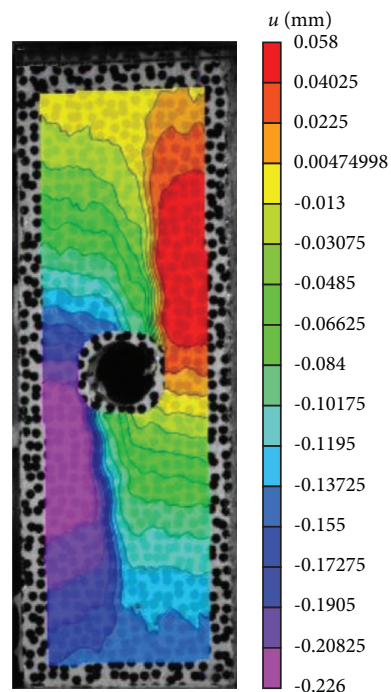

(g)

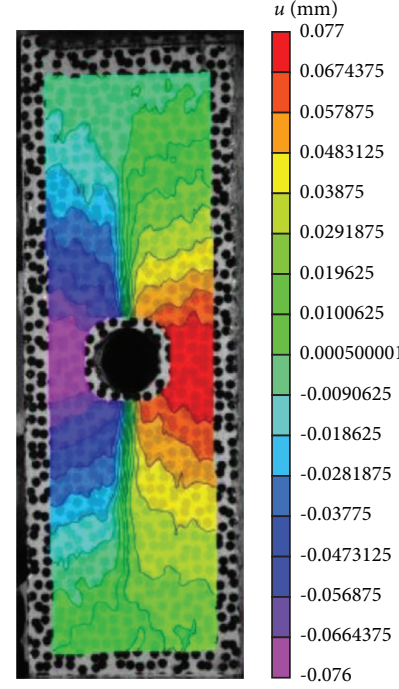

(d)

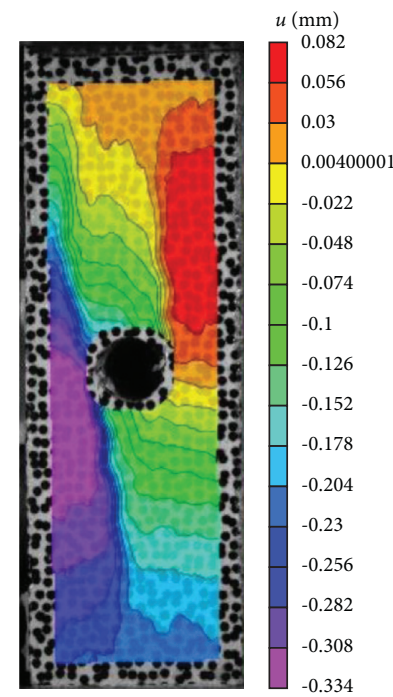

(h)

Figure 13: The nephogram of the horizontal displacement field at different stress levels corresponding to points A-H in Figure 12. 


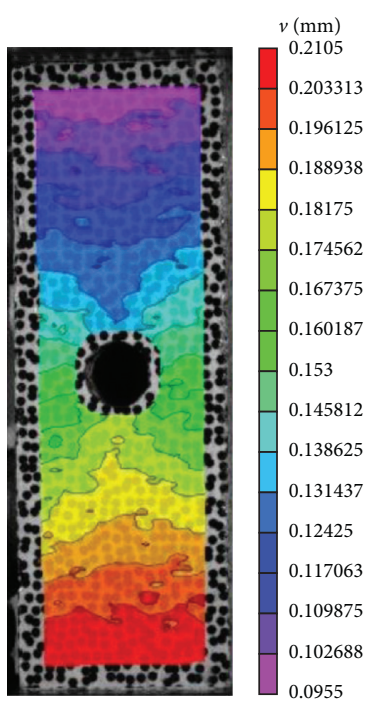

(a)

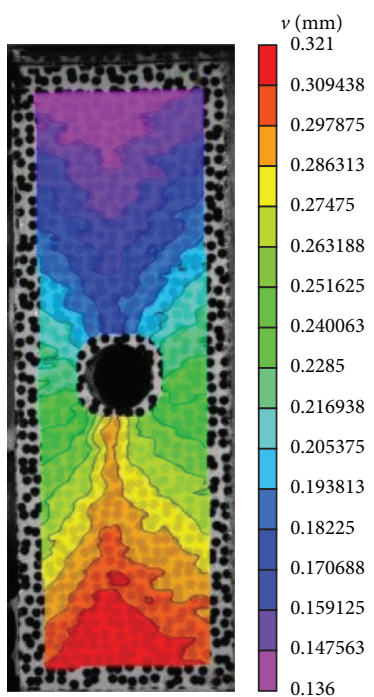

(e)

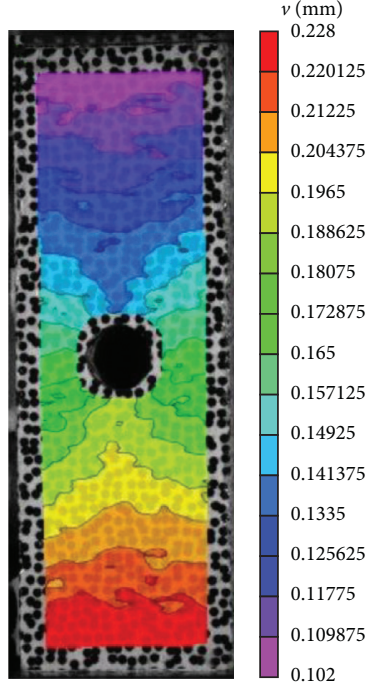

(b)

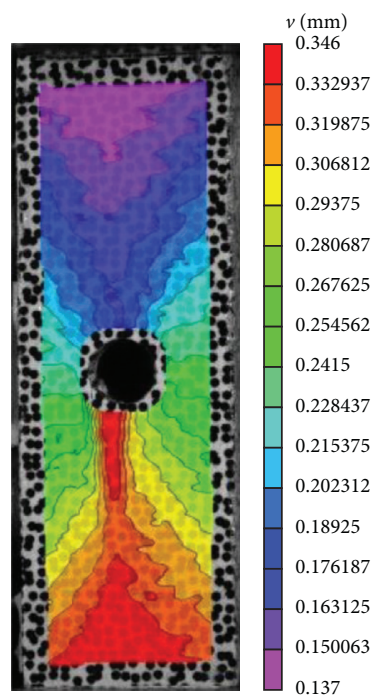

(f)

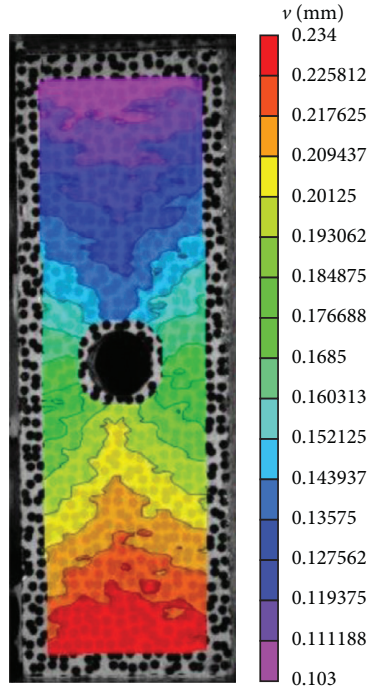

(c)

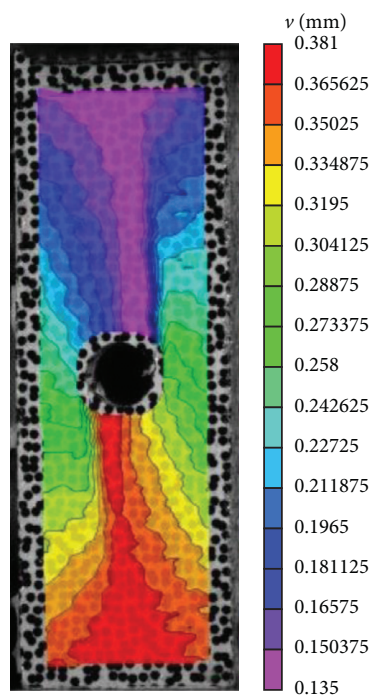

(g)

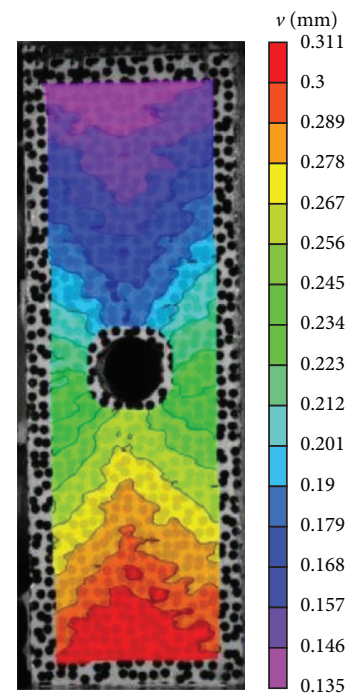

(d)

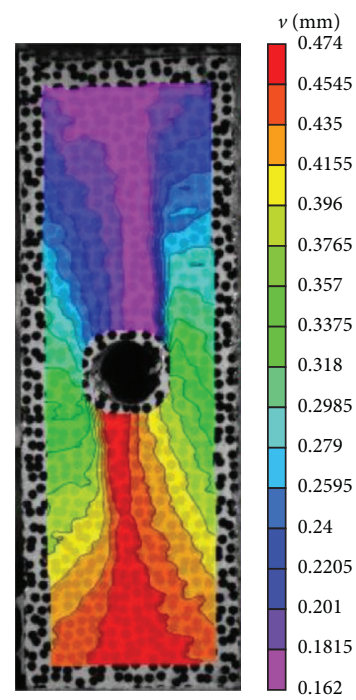

(h)

Figure 14: The nephogram of the vertical displacement field at different stress levels corresponding to points A-H in Figure 12.

the stress concentration area at point $\mathrm{A}$ is approximately $2.16 \times 10^{-3}$, which is far greater than the critical tensile strain, indicating that point $\mathrm{A}$ is in the stages of tensile stress concentration and crack initiation. With increasing load, the range of the stress concentration area and the value of the major principal strain further increase, and the two macroscopic stress concentration zones are parallel to the principal stress direction (Figures 15(b)-15(d)). As the loading continues, the stress concentration area directly under the opening transfers to the lower left of the opening (Figure 15(e)), which means the cracks will be initiated in the lower left of the opening. Subsequently, the stress concentration area just above the opening is transferred to the upper right of the opening (Figures 15(f) and 15(g)), indicating that cracks will also occur in the upper right of the cavern, which is distributed diagonally and symmetrically with the stress concentration zone in the lower left of the opening. The stress acting on the specimen is still increasing, but the peak strength of the specimen has not yet been reached, implying that macroscopic fracture of the sample appears before reaching the peak strength. When the peak strength is reached, the major principal strain increases to the maximum value of $4.46 \times 10^{-2}$, and a stress concentration zone appears at the upper left of the opening and extends to the upper left corner of the sample (Figure 15(h)), suggesting the formation of secondary cracks. The microcracks on the left and right sides of the opening obviously tend to develop further to the original direction, and the crack area almost penetrates the whole specimen and eventually evolves into macrocracks, which causes the failure of the sample. In addition, the local tensile deformation concentration area generated directly above and below the opening almost disappears. After the test, it is observed that the stress concentration area identified by the image 


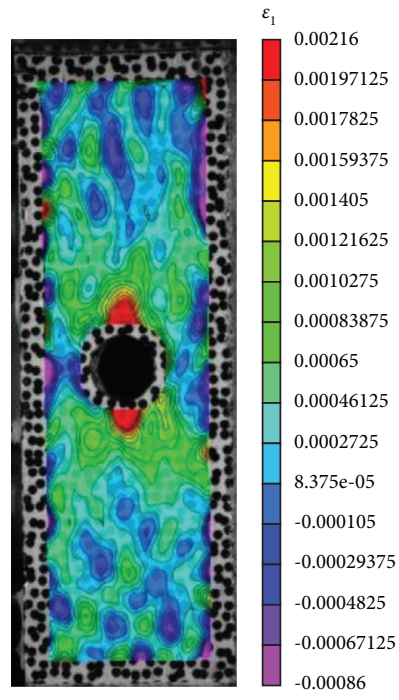

(a)

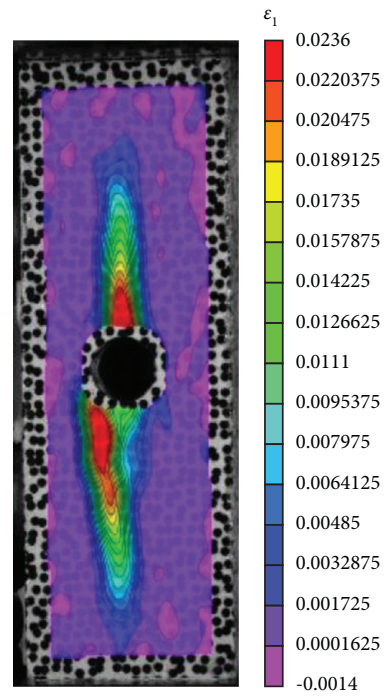

(e)

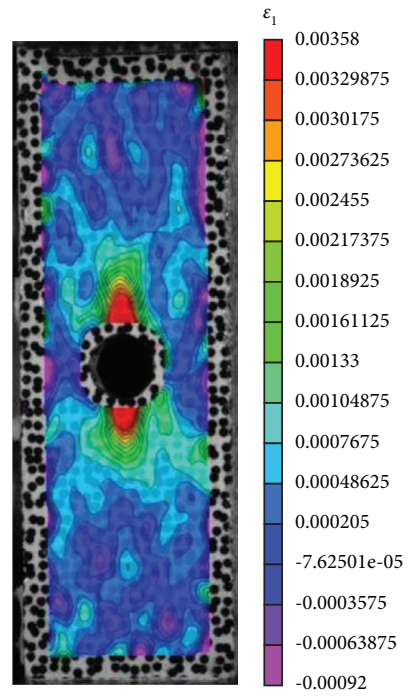

(b)

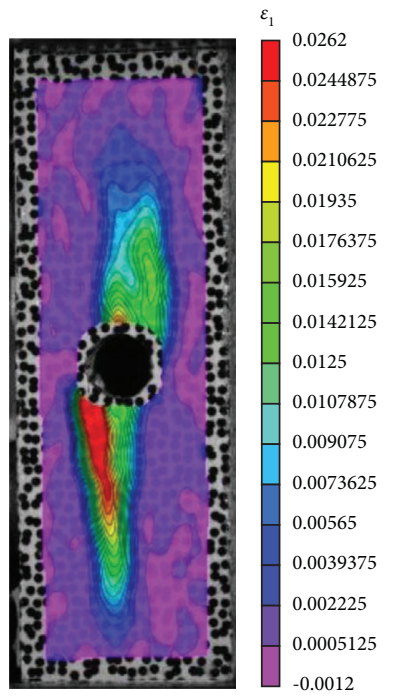

(f)

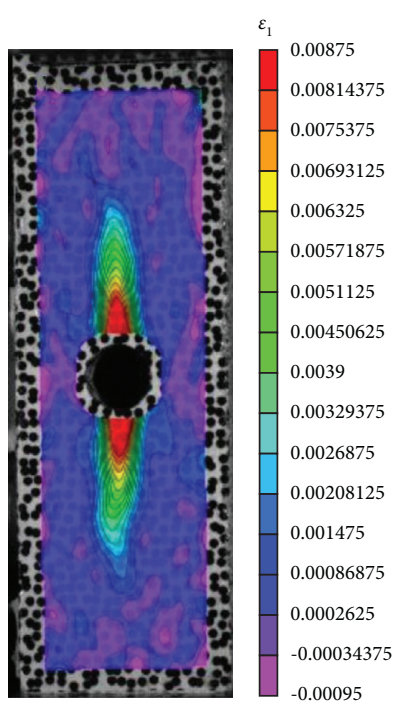

(c)

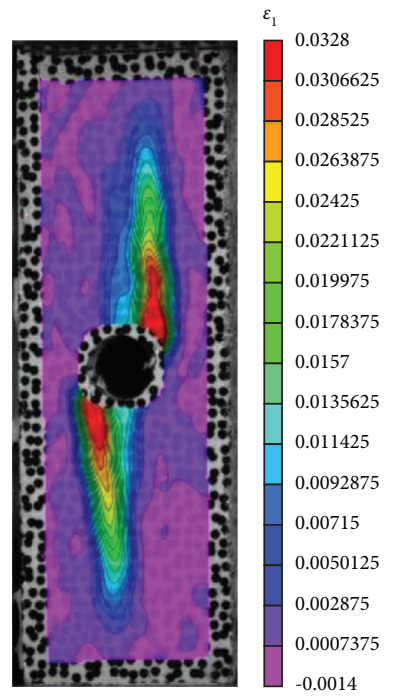

(g)

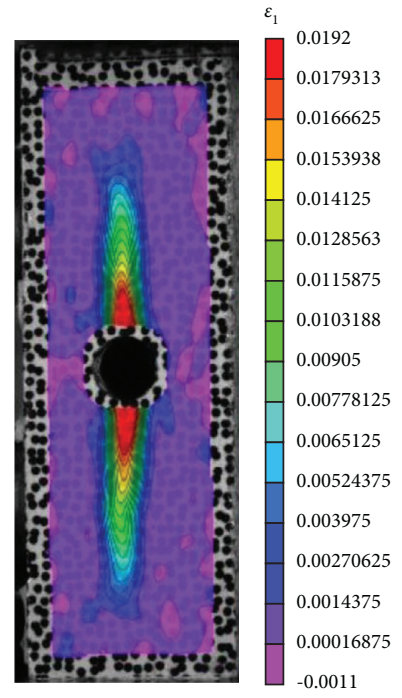

(d)

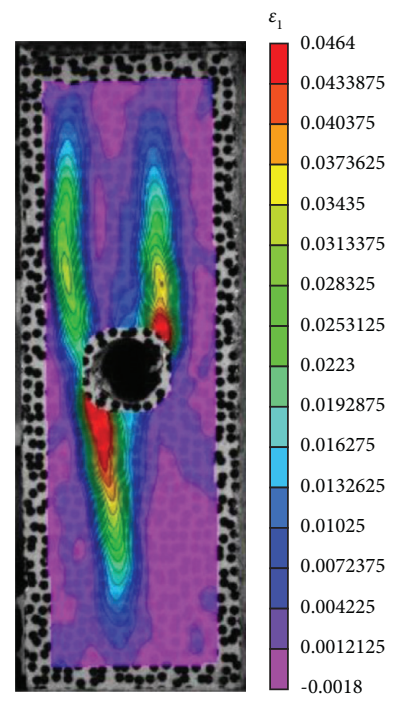

(h)

FIgURE 15: Nephogram of the major principal strain field at different stress levels corresponding to points A-H in Figure 12.

corresponds to the propagation path of the visible fracture of the specimen.

The deformation and failure process of the intact specimen containing an opening show that the failure of brittle rock involves the initiation and growth of microcracks and that the initiation of microcracks is primarily caused by the stress concentration around the opening in the specimen. During uniaxial loading, the initiation of new cracks begins at the tip of the original microcracks in the sample, and only microcracks with appropriate direction and size will form new microcracks at their tips. After the rock reaches a stable crack propagation stage, unstable crack propagation begins under crack damage stress, which eventually leads to specimen failure. Due to the heterogeneity of rock materials, there will always be a dominant crack, which causes the failure of the intact specimen containing an opening that is not completely symmetrical.
During the loading process, the propagation direction of the macrocracks formed on both sides of the opening is generally in line with the loading direction. Notably, there is an interesting phenomenon in the failure process of the intact specimen containing an opening; that is, the high strain zone representing the initial tensile crack directly above and below the opening will not extend to the end of the specimen after a certain stage of development but will gradually disappear with the formation of secondary cracks. This can be explained by the fact that with increasing load, the tensile stress is gradually transformed into compressive stress after passing a certain distance from the upper and lower boundaries of the opening, which will be further clarified according to the later theoretical calculation results.

In conclusion, the evolution process of the deformation field of the intact specimen containing an opening is from an overall uniform distribution to a prominent local 
deformation. Finally, it was observed that the deformation of the local area near the opening is significantly greater than that of other areas. As the only defect in the specimen, a high stress concentration is formed around the cavern during loading, and crack initiation begins around the opening. The growth of tensile cracks around the cavern is primarily influenced by the nucleation and development of the generated strain localization zone.

4.2. Crack Evolution Process and Failure Pattern. The process of crack evolution could be regarded as a function of the original microcrack distribution and interaction relationship [27]. Analyzing the crack propagation process of an intact specimen containing an opening is helpful for understanding the deformation and failure characteristics under different stress states. In the loading process, due to the existence of the opening, stress concentration will occur around the opening, and new cracks begin to emerge as the stress intensity factor around the opening reaches the fracture toughness.

Figure 16 shows the crack propagation process and failure pattern of the intact specimen containing an opening. In Figure 16, “T" represents tensile cracks, " $\mathrm{S}$ " denotes shear cracks, the white circle stands for circled white patches, the numbers mean the time sequence of occurrence, and the letters after numbers are used to distinguish cracks appearing in different parts of the specimen at the same time. Under the action of loading, two vertical tensile cracks (T1a and T1b) appear simultaneously at the stress concentration position at the bottom of the opening and propagate upward and downward, respectively. However, these two cracks will not develop into the main failure surface. Subsequently, tensile cracks (T2, T4, and T5) are initiated successively at the lower left, right, and left stress concentration parts of the opening; tensile crack T3 appears at the lower part of the specimen, which expands toward their initial initiation direction, and the crack width also expands continuously. The growth path of these tensile cracks is not completely parallel to the loading direction but zigzag through the sample, which may be because the cracks always propagate along the boundary of large mineral particles in the granite matrix. These cracks have long trace lengths and interact with each other to form multiple macroscopic fracture surfaces, which eventually causes unstable failure of the sample. In addition, small-scale shear cracks (S4 and S6) appear on both sides of the opening, and far-field cracks (such as T7) appear in the upper left corner of the specimen because of brittle failure. Generally, the position of the initial crack around the opening during loading is the orientation or normal orientation of the maximum principal stress, and the orientation of the macroscopic cracks is roughly consistent with that of the maximum principal stress. Note that during the deformation and failure of the specimen, white patches appear in many parts of the specimen surface, which is considered the result of microcrack nucleation.

For the fracture mechanism of the specimen containing an opening, the fracture of all brittle materials involves the collapse of microscopic and submicroscopic cavities [10].
Under laboratory loading conditions, as the axial deformation increases, the specimen usually shows slow and stable fracture evolution, i.e., initial tensile cracks, secondary or far-field cracks, and compression failure. The main tensile fractures are recognized again because they were formed in response to predictable tensile stress. Similarly, due to the presence of a high compression stress concentration, the compression zone around the cavern will be broken. The origin of secondary or far-field cracks is not noticeable, and they have formed far away from the cavern, so they may not be seen in underground engineering [11]. However, the tensile stress at the remote location may become large enough to nucleate and then propagate tensile fracture in a stable and load-controlled manner, which together with the cracks around the cavity leads to the collapse of the cavity.

\subsection{Stress Distribution Characteristics around an Opening.} A rock mass with an opening can be regarded as a defective rock mass, and its fracture behavior is very complex, which mainly depends on the evolution of cracks during loading. The failure behavior of the surrounding rock of the cavern is closely correlated with the stress distribution around the cavern under corresponding loading conditions. To deeply understand the crack evolution and failure pattern of the specimen containing an opening, it is necessary to briefly analyze the stress distribution characteristics around the opening. To facilitate theoretical derivation, the stress acting on the opening is usually simplified as plane stress, and the stress distribution around the opening under biaxial stress can be calculated based on two-dimensional elastic theory. The theoretical analysis model is illustrated in Figure 17.

The radial stress $\sigma_{r}$, tangential stress $\sigma_{\theta}$, and shear stress $\tau_{r \theta}$ acting on the cavern boundary at the distance $r$ from the center of the cavern can be given by Kirsch's solution [14]:

$$
\left\{\begin{array}{l}
\sigma_{r}=\frac{1}{2}(1+k) P\left(1-\frac{R_{0}^{2}}{r^{2}}\right)-\frac{1}{2}(1-k) P\left(1-4 \frac{R_{0}^{2}}{r^{2}}+3 \frac{R_{0}^{4}}{r^{4}}\right) \cos 2 \theta \\
\sigma_{\theta}=\frac{1}{2}(1+k) P\left(1+\frac{R_{0}^{2}}{r^{2}}\right)+\frac{1}{2}(1-k) P\left(1+3 \frac{R_{0}^{4}}{r^{4}}\right) \cos 2 \theta \\
\tau_{r \theta}=\frac{1}{2}(1-k) P\left(1+2 \frac{R_{0}^{2}}{r^{2}}-3 \frac{R_{0}^{4}}{r^{4}}\right) \sin 2 \theta
\end{array}\right.
$$

where $\theta$ is the angle between the radius and the horizontal axis; $P$ represents the vertical stress; and $k$ denotes the lateral pressure coefficient.

Under uniaxial loading conditions, $r=R_{0}$ and $k=0$, the stress distribution equation at the opening boundary can be transformed from equation (2) to

$$
\left\{\begin{array}{l}
\sigma_{r}=\tau_{r \theta}=0, \\
\sigma_{\theta}=P(1+2 \cos 2 \theta) .
\end{array}\right.
$$

According to equation (3), the static tangential stress distribution around the opening can be obtained as plotted in Figure 18(a). $\sigma_{\theta}$ along the cavern is characterized by a line 


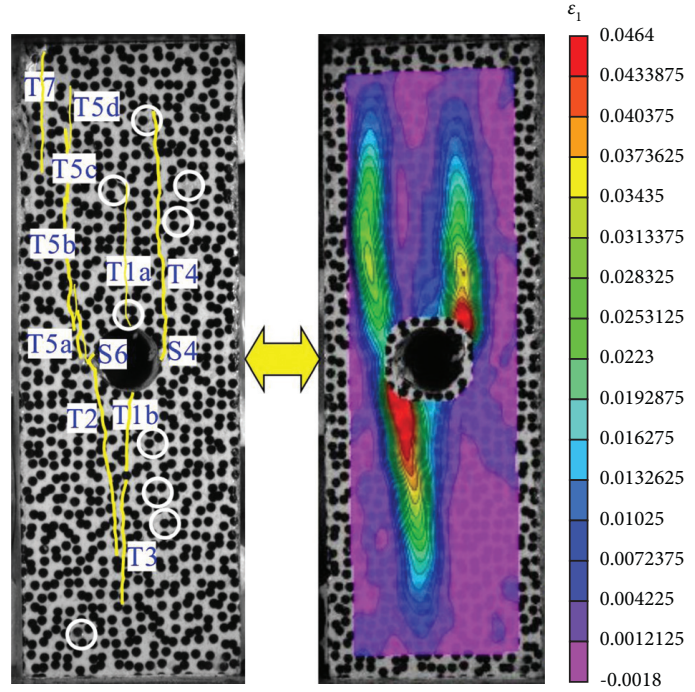

FIGURE 16: Crack propagation process and failure pattern of the intact specimen containing an opening.

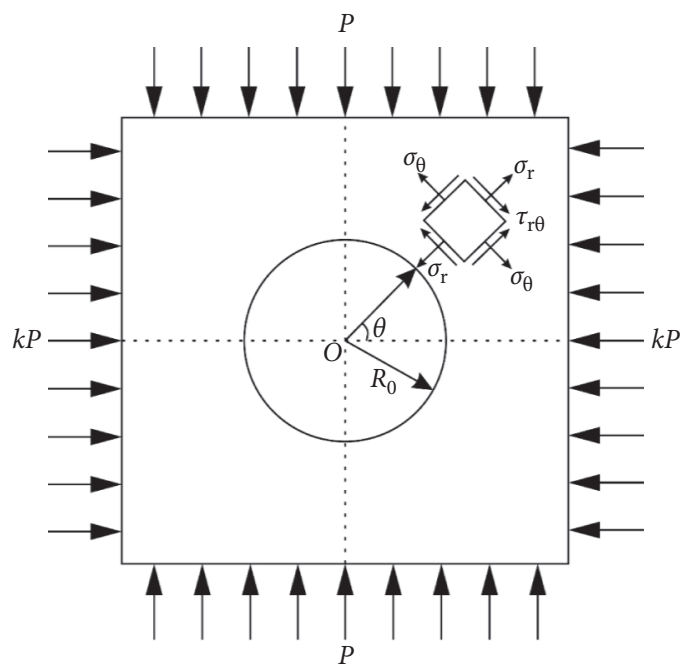

FIGURE 17: Loading conditions around the circular cavern in an infinite plane.

segment perpendicular to the cavern, and the length of the line segment represents the relative magnitude of the local tangential stress. When the line segment is outside the cavern, $\sigma_{\theta}$ is positive, and vice versa. The tensile stress concentration coefficient around the top and bottom of the cavern is 1.0, while the compressive stress concentration coefficient around the two sides of the cavern is 3.0. The tensile stress zone is distributed at the top and bottom of the opening with the maximum value of $P$, and the tensile stress will play a leading role in fracturing in this area. The cracks that appeared in the tensile stress concentration zone are called tensile cracks. Accordingly, the compressive stress concentration zone is located at the left and right sides of the opening with the maximum value of $3 P$. Because of the existence of a high compressive stress concentration, shear failure may occur in the compressive zone around the opening.
In addition, to further understand the fracture properties around the opening, Goodier [29] deduced a closed solution to estimate the stress concentration around the spherical particles in the matrix under far-field compressive stress. According to Goodier's solution, the stress distribution around the opening in an infinite plane under the action of vertical far-field uniaxial compression stress is computed and the change in the concentration coefficient of $\sigma_{\theta}$ is given, as plotted in Figure 18(b) [28]. Interestingly, the high tangential compression stress concentration coefficient at the left and right sides of the cavern is also 3.0, and the medium tensile stress concentration coefficient at the top and bottom of the cavern is 1.0 , which agrees fairly well with the results provided by Kirsch's solution. Moreover, the tensile stress gradually transforms into compressive stress after a certain distance from the upper and lower boundaries of the opening, which can explain why the tensile cracks 


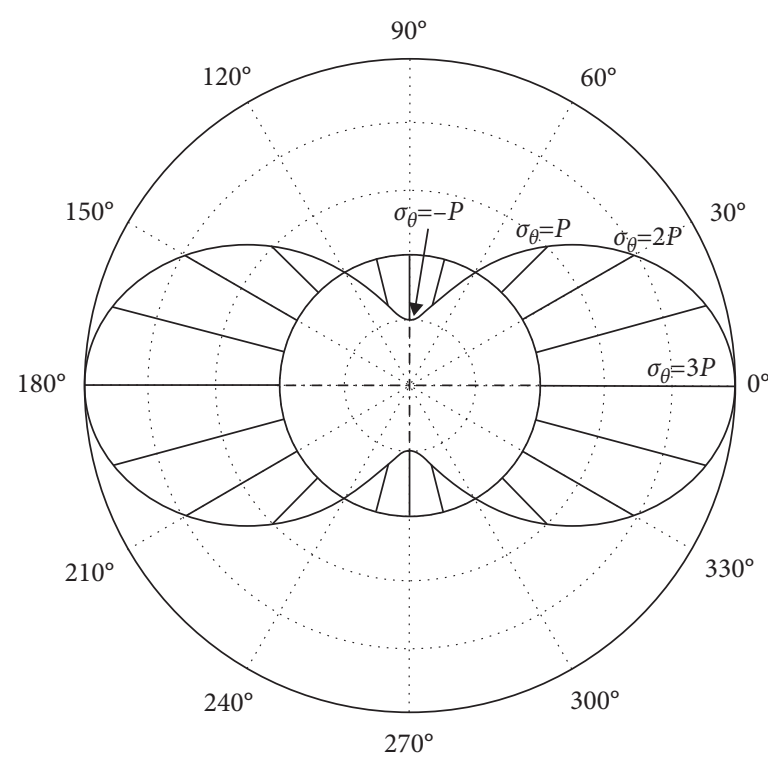

(a)

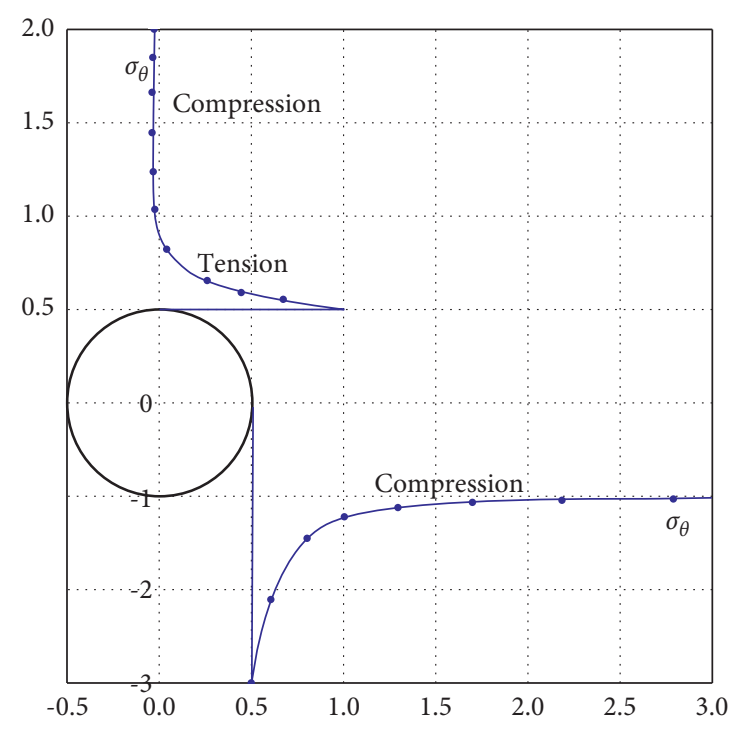

(b)

FIgURE 18: Static stress distribution (a) and stress transformation (b) [28] around the opening under uniaxial loading.

observed in this experiment first occurred at the top and bottom of the opening but did not propagate into the macroscopic tensile cracks that led to the ultimate failure of the specimen. The above analysis suggests that the test results of the fracture characteristics of the intact sample containing an opening are in accordance with the theoretical analysis results. It should be noted that the static tangential stress distribution around the opening illustrated in Figure 18 is mainly for an infinite body, which may not be fully applicable to the small-sized samples designed in this study, but it still has important reference value and can guide the analysis of the test results.

4.4. Comparison with Similar Studies. As noted previously, some similar studies have been performed on rock samples with a circular opening. To fully understand the failure of the opening, some typical failure modes of samples containing a circular opening obtained from various experiments under uniaxial compression were selected for comparison with our research results, as presented in Figure 19. Zhu et al. [18] studied the failure characteristics of sandstone samples containing a round cavity using the DIC technology. Tensileshear mixed failure mainly appears in the sample (Figure 19(a)), which was penetrated by one or two macroscopic shear cracks, showing obvious scratches and rock debris on the fracture surface. Similarly, mixed shear and tensile fractures were also observed in the sandstone sample with an opening (Figure 19(b)) [21], showing an ultimate failure pattern similar to that in Figure 19(a). For the failure characteristics of granite samples with a circular hole provided by Weng et al. [16], in addition to the formation of macroscopic shear cracks and tensile cracks around the opening, some shear failures were also observed to occur in remote areas of the cavity (Figure 19(c)). The failure of the specimen tends to be shear failure. According to the $\mathrm{AE}$ signals and moment tensor analysis, the spatial position and type of microcracks in granite samples with a circular cavern were obtained by Liu et al. [30], as shown in Figure 19(d). Clearly, the tensile microcracks were concentrated on the top, while the shear microcracks were mainly on the sidewall of the cavity, which means that the main crack is a combination of shear and tensile cracks. Using the same methods as Liu et al. [30], Xu et al. [15] found that as the stress increases, the microcracks gathered at the top and lower left side of the granite sample with a round hole at the initial loading stage continue to propagate to the end of the sample, and finally, two macroscopic cracks were formed (Figure 19(e)). The failure of the specimen was tensile, although some shear cracks were also observed. The findings of the last two studies further validate the conclusions obtained in this study, that is, the three dominant macroscopic tension cracks and the small-scale shear cracks on the sidewall of the hole shown in Figure 16.

Notably, for the failure characteristics of specimens with a circular hole, not all of the previous research results are consistent with the conclusions of this study. This phenomenon is not surprising since the deformation and failure characteristics of the chamber are related to many endogenous and exogenous factors, such as lithology, sample size, experimental equipment, loading condition, and processing quality of the sample. It is precisely because of the influence of these factors that the failure modes of the specimens show the characteristics of diversity and unpredictability, which can be better reflected under engineering field conditions.

\section{Discussion}

One of the difficulties in underground engineering construction is to predict the possible failure modes in the next excavation or service process according to the revealed 

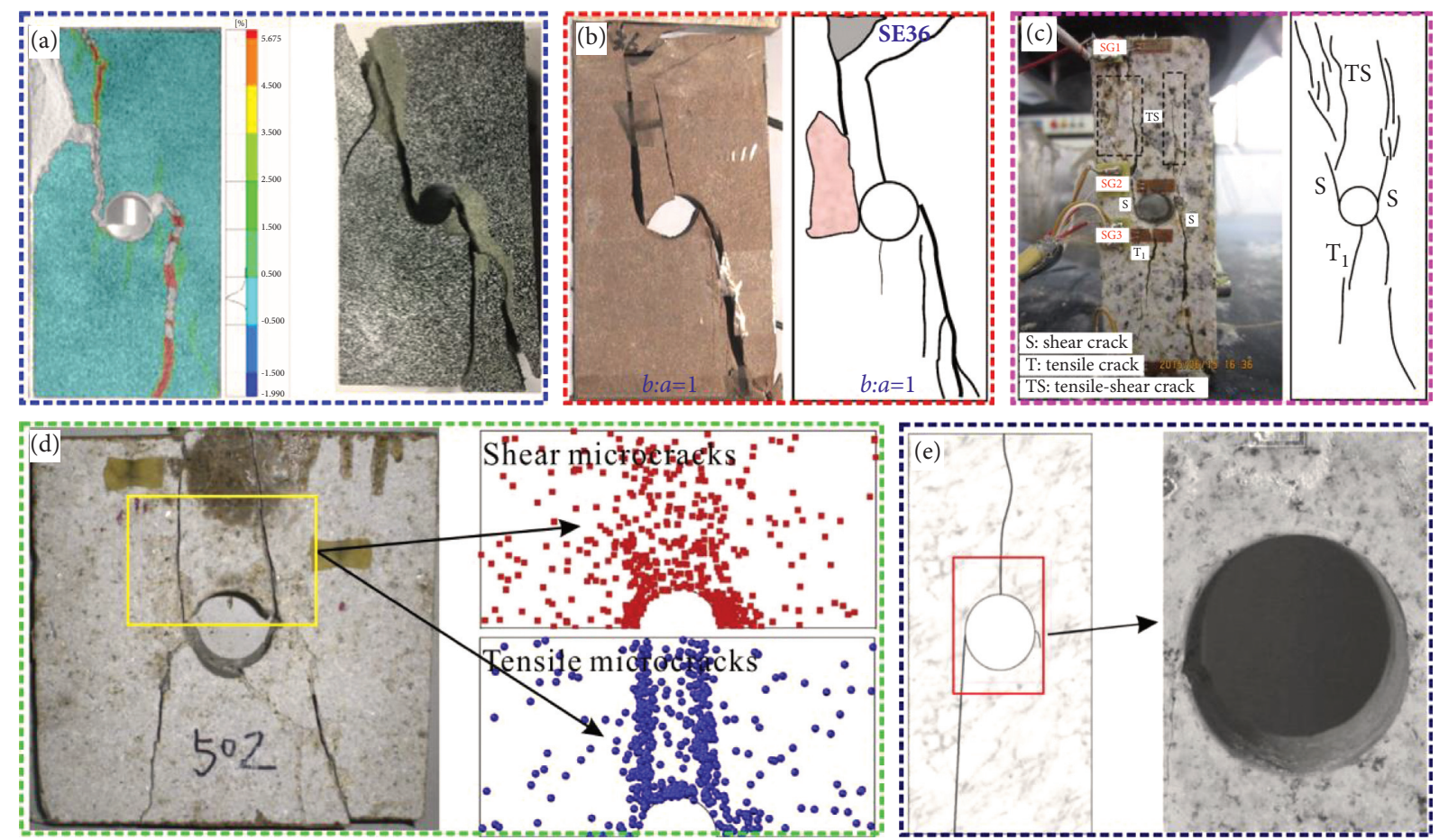

FIGURE 19: Failure patterns of samples with a circular cavity obtained from different experiments under uniaxial loading: (a) after Zhu et al. [18]; (b) after Huang et al. [21]; (c) after Weng et al. [16]; (d) after Liu et al. [30]; (e) after Xu et al. [15].

geological information and surrounding rock failure phenomenon to formulate targeted prevention and control measures. Therefore, the failure mode analysis of the surrounding rock of the cavern is the basic basis for chamber stability analysis and design and the calculation of supporting parameters and is also important for explaining the whole cracking sequence and failure mechanism of the surrounding rock under loading.

According to the research results of the failure mechanism of the surrounding rock worldwide, the rock containing an opening can be divided into two categories [31]: one is to regard the opening as an excavation chamber (such as this study) and investigate the evolution law of cracks around the opening from the perspective of excavation damage; and the other is to regard the opening as the initial damage in the rock mass, and the crack accumulation process, propagation path, strength and deformation characteristics of the rock mass having an opening are analyzed from the angle of damage and fracture mechanics. Theoretically, the evolution laws of cracks around the chamber are different in these two cases. On the other hand, after summarizing the research results of this study and previous studies, it is found that with a change in experimental conditions, the crack propagation patterns are quite different, and the surrounding rock of the cavern indicates different failure modes. Generally, the failure modes of the surrounding rock are primarily tension failure, shear failure, and mixed tension-shear failure, which mainly depend on the stress state of the surrounding rock and its properties. This finding is basically consistent with the actual failure cause analysis results of the surrounding rock. Due to the influence or control of a variety of endogenous and exogenous factors, the damage of the surrounding rock is highly nonlinear and uncertain, which makes it difficult to accurately predict the failure pattern of the surrounding rock in engineering practice, thus increasing the probability of chamber disasters.

In addition, according to rock damage-fracture mechanics theory, the experimental study in this paper provides reliable acousto-optic mechanical parameters to determine the stress evolution and crack development state around an underground engineering chamber. The comprehensive analysis of acousto-optic mechanical data shows that the cracking process of the surrounding rock of the cavern occurs gradually under quasistatic loading, including the propagation and coalescence of original cracks and new cracks in the surrounding rock of the cavern as well as the final formation of the macroscopic fracture surface. Essentially, the nucleation at the top and bottom of the cavern indicates the initiation of microcracks in the surrounding rock, and the stable crack propagation means a process controlled by the limited propagation of a few macroscopic cracks, while the unstable crack propagation indicates the acceleration of subcritical crack propagation. The initial tensile cracks and local smallscale shear fractures are formed at tensile and compressive stress concentration points, which exist around the cavern without fracture. For the main rock mass of brittle granite, the deformation around the underground cavern is dominated by the tensile failure of the main rock mass. Because of the selfsimilarity of the geological structure, the laboratory-scale test results can be regarded as basically suitable for large-scale engineering applications, such as tunnels, mining, and radioactive waste treatment facilities. More importantly, the activity of microcracks generated during the deformation of 
the surrounding rock could be quantitatively described by the $\mathrm{AE}$ counts and energy. In engineering practice, the detailed statistics of AE or microseismic signals could be expected to yield a precursor for the catastrophic fracture of the surrounding rock of the cavern, and effective prevention and control measures can be taken in time to avoid the occurrence of cavern disasters. Furthermore, the DIC technique will be helpful to analyze and understand the deformation and failure of the surrounding rock of the cavern.

\section{Conclusions}

(1) The existence of openings in rock specimens will cause degradation of the mechanical properties. Under the uniaxial compression condition, the AE signals produced by the intact specimen and the intact specimen containing an opening at each deformation stage have different characteristics. The change trends of AE counts, cumulative counts, energy, cumulative energy, b-value, peak frequency, and amplitude with time are generally consistent during uniaxial compression, which can well reflect the internal damage and failure process of the samples. These parameters have a good ability to identify precursors and can be used as precursory signals to determine the failure of specimens. Therefore, AE monitoring can be used to characterize the microscopic damage and evolution process of the samples, and the precursor signals can be used to predict the macroscopic instability and failure of the field engineering rock mass.

(2) The evolution process of the deformation field of the intact specimen containing an opening is from an overall uniform distribution to a prominent local deformation, and the deformation of the local area near the cavern is obviously larger than that of other areas. The initiation of cracks begins around the opening, and the growth of tensile cracks around the opening is primarily influenced by the nucleation and propagation of the generated strain localization area. The tensile stress gradually transforms into compressive stress after a certain distance from the upper and lower boundaries of the opening, which can explain why the tensile cracks observed in this experiment first occurred at the top and bottom of the opening but did not propagate into the macroscopic tensile cracks that led to the ultimate failure of the specimen.

(3) The DIC technique has unique advantages in geotechnical mechanics tests, and the evolution of the strain field in the process of rock material failure can better reflect the law of crack generation and propagation on the rock surface. Hence, DIC images can be combined with AE monitoring to capture the evolution sequence of crack propagation, which has the potential to accurately reveal the deformation and failure mechanism of the surrounding rock of the opening.

\section{Data Availability}

The test data used to support the findings of this study are included within the article.

\section{Conflicts of Interest}

The authors declare that they have no known competing financial interests or personal relationships that could have appeared to influence the work reported in this study.

\section{Acknowledgments}

This research was financially supported by the Fundamental Research Funds for the Central Universities (no. FRF-TP20-041A1), the National Natural Science Foundation of China (nos. U2034206 and 52074020), and the State Key Research Development Program of China (no. 2016YFC0600801).

\section{References}

[1] P. Li and M.-f. Cai, "Energy evolution mechanism and failure criteria of jointed surrounding rock under uniaxial compression," Journal of Central South University, vol. 28, no. 6, pp. 1857-1874, 2021.

[2] X. Wu, Q. Guo, P. Li, F. Ren, J. Zhang, and M. Cai, "Investigating the effect of temperature changes on the physical field of surrounding rock in a deep gold mine," Advances in Materials Science and Engineering, vol. 2021, Article ID 8490864, 13 pages, 2021.

[3] L. Tan, T. Ren, L. Dou, X. Yang, M. Qiao, and H. Peng, "Analytical stress solution and mechanical properties for rock mass containing a hole with complex shape," Theoretical and Applied Fracture Mechanics, vol. 114, Article ID 103002, 2021.

[4] D. Mas Ivars, M. E. Pierce, C. Darcel et al., "The synthetic rock mass approach for jointed rock mass modelling," International Journal of Rock Mechanics and Mining Sciences, vol. 48, no. 2, pp. 219-244, 2011.

[5] P. Li, F.-h. Ren, M.-f. Cai, Q.-f. Guo, H.-f. Wang, and K. Liu, "Investigating the mechanical and acoustic emission characteristics of brittle failure around a circular opening under uniaxial loading," International Journal of Minerals, Metallurgy, and Materials, vol. 26, no. 10, pp. 1217-1230, 2019.

[6] J. B. Martino and N. A. Chandler, "Excavation-induced damage studies at the underground research laboratory," International Journal of Rock Mechanics and Mining Sciences, vol. 41, no. 8, pp. 1413-1426, 2004.

[7] P. Li, M.-f. Cai, Q.-f. Guo, and S.-j. Miao, "Characteristics and implications of stress state in a gold mine in Ludong area, China," International Journal of Minerals, Metallurgy, and Materials, vol. 25, no. 12, pp. 1363-1372, 2018.

[8] X. T. Feng, S. Y. Wu, S. J. Li et al., "Comprehensive field monitoring of deep tunnels at Jinping underground laboratory(CJPL-II) in China," Chinese Journal of Rock Mechanics and Engineering, vol. 35, pp. 649-657, 2016.

[9] R. S. Read, "20 years of excavation response studies at AECL's Underground Research Laboratory," International Journal of Rock Mechanics and Mining Sciences, vol. 41, no. 8, pp. 1251-1275, 2004.

[10] E. Z. Lajtai and V. N. Lajtai, “The collapse of cavities," International Journal of Rock Mechanics and Mining Science \& Geomechanics Abstracts, vol. 12, no. 4, pp. 81-86, 1975. 
[11] B. J. Carter, E. Z. Lajtai, and A. Petukhov, "Primary and remote fracture around underground cavities," International Journal for Numerical and Analytical Methods in Geomechanics, vol. 15, no. 1, pp. 21-40, 1991.

[12] A. Fakhimi, F. Carvalho, T. Ishida, and J. F. Labuz, "Simulation of failure around a circular opening in rock," International Journal of Rock Mechanics and Mining Sciences, vol. 39, no. 4, pp. 507-515, 2002.

[13] X.-d. Zhao, H.-x. Zhang, and W.-c. Zhu, "Fracture evolution around pre-existing cylindrical cavities in brittle rocks under uniaxial compression," Transactions of Nonferrous Metals Society of China, vol. 24, no. 3, pp. 806-815, 2014.

[14] D. Li, Q. Zhu, Z. Zhou, X. Li, and P. G. Ranjith, "Fracture analysis of marble specimens with a hole under uniaxial compression by digital image correlation," Engineering Fracture Mechanics, vol. 183, pp. 109-124, 2017.

[15] S.-d. Xu, Y.-h. Li, and J.-p. Liu, "Detection of cracking and damage mechanisms in brittle granites by moment tensor analysis of acoustic emission signals," Acoustical Physics, vol. 63, no. 3, pp. 359-367, 2017.

[16] L. Weng, X. Li, A. Taheri, Q. Wu, and X. Xie, "Fracture evolution around a cavity in brittle rock under uniaxial compression and coupled static-dynamic loads," Rock Mechanics and Rock Engineering, vol. 51, no. 2, pp. 531-545, 2018.

[17] F. Feng, X. Li, J. Rostami, and D. Li, "Modeling hard rock failure induced by structural planes around deep circular tunnels," Engineering Fracture Mechanics, vol. 205, pp. 152174, 2018.

[18] Q. Zhu, D. Li, Z. Han, X. Li, and Z. Zhou, "Mechanical properties and fracture evolution of sandstone specimens containing different inclusions under uniaxial compression," International Journal of Rock Mechanics and Mining Sciences, vol. 115, pp. 33-47, 2019.

[19] Z. Zhou, L. Tan, W. Cao, Z. Zhou, and X. Cai, "Fracture evolution and failure behaviour of marble specimens containing rectangular cavities under uniaxial loading," Engineering Fracture Mechanics, vol. 184, pp. 183-201, 2017.

[20] Z. Song, H. Konietzky, and X. Cai, "Modulus degradation of concrete exposed to compressive fatigue loading: insights from lab testing," Structural Engineering \& Mechanics, vol. 78, pp. 281-296, 2021.

[21] Y.-H. Huang, S.-Q. Yang, M. R. Hall, W.-L. Tian, and P.-F. Yin, "Experimental study on uniaxial mechanical properties and crack propagation in sandstone containing a single oval cavity," Archives of Civil and Mechanical Engineering, vol. 18, no. 4, pp. 1359-1373, 2018.

[22] Z. Song, Y. Wang, H. Konietzky, and X. Cai, "Mechanical behavior of marble exposed to freeze-thaw-fatigue loading," International Journal of Rock Mechanics and Mining Sciences, vol. 138, Article ID 104648, 2021.

[23] B. Gutenberg and C. F. Richter, "Frequency of earthquakes in California," Bulletin of the Seismological Society of America, vol. 34, pp. 185-188, 1994.

[24] L. M. Zhang, S. Q. Ma, M. Y. Ren, S. Q. Jiang, Z. Q. Wang, and J. L. Wang, "Acoustic emission frequency and b value characteristics in rock failure process under various confining pressures," Chinese Journal of Rock Mechanics and Engineering, vol. 34, pp. 2057-2063, 2015.

[25] Y. B. Zhang, P. Liang, B. Z. Tian, X. L. Yao, L. Sun, and X. X. Liu, "Multi parameter coupling analysis of acoustic emission signals of granite disaster and the precursor characteristics of the main rupture," Chinese Journal of Rock Mechanics and Engineering, vol. 35, pp. 2248-2258, 2016.
[26] S. De Santis and A. K. Tomor, "Laboratory and field studies on the use of acoustic emission for masonry bridges," NDT \& E International, vol. 55, pp. 64-74, 2013.

[27] A. Basu and D. A. Mishra, "A method for estimating crackinitiation stress of rock materials by porosity," Journal of the Geological Society of India, vol. 84, no. 4, pp. 397-405, 2014.

[28] R. P. Janeiro and H. H. Einstein, "Experimental study of the cracking behavior of specimens containing inclusions (under uniaxial compression)," International Journal of Fracture, vol. 164, no. 1, pp. 83-102, 2010.

[29] J. N. Goodier, "Concentration of stress around spherical and cylindrical inclusions and flaws," Journal of Applied Mechanics, vol. 1, no. 2, pp. 39-44, 1933.

[30] J.-p. Liu, Y.-h. Li, S.-d. Xu, S. Xu, C.-y. Jin, and Z.-s. Liu, "Moment tensor analysis of acoustic emission for cracking mechanisms in rock with a pre-cut circular hole under uniaxial compression," Engineering Fracture Mechanics, vol. 135, pp. 206-218, 2015.

[31] J. Y. Teng, J. X. Tang, and X. Y. Li, "Mechanical property and fracture propagation of anchored rock with a hole under uniaxial compression," Chinese Journal of Rock Mechanics and Engineering, vol. 37, pp. 87-103, 2018. 